Çankırı Karatekin Üniversitesi

İktisadi ve İdari Bilimler

Fakültesi Dergisi

Y. 2019, Cilt 9, Say1 2, ss. 559-591
Cankırı Karatekin University

Journal of the Faculty of Economics and Administrative Sciences

Y. 2019, Volume 9, Issue 2, pp. 559-591

Araştırma Makalesi

\title{
Gri Hedef Programlama ile İşgücü Çizelgeleme Karar Problemlerinin Çözümü ${ }^{1}$
}

\author{
Gülper BASMACI \\ Sorumlu Yazar, Dokuz Eylül Üniversitesi IIIBF, Işsletme Bölümü \\ gulper.basmaci@deu.edu.tr, ORCID:0000-0002-8038-9639
}

Aslı ÖZDEMİR

Dokuz Eylül Üniversitesi İ̈BF, İşletme Bölümü

asli.yuksek@deu.edu.tr, ORCID: 0000-0003-4494-5818

\begin{abstract}
$\ddot{O} z$
İşgücü çizelgeleme karar problemleri vardiyalı ve düzensiz iş günlerinde çalışan işletmelerin çözmesi gereken zor ve zaman alıcı bir sorundur. Günümüz rekabet koşulları düşünüldüğünde belirsizlik altında kararlar almak kaçınılmaz olmaktadır. Gri Sistem Teorisi eksik bilgiden kaynaklanan belirsizliğin modellenmesinde kullanılan yöntemler içermektedir. Hedef Programlama yöntemi ise karar problemini sınırlayan kısıtlar çerçevesinde belirlenmiş hedeflerden sapmaları minimize edecek tatmin edici çözümler sunmaktadır. İşücü çizelgeleme karar problemi karar vericinin birden fazla hedefe sahip olduğu bir karar problemi çeşididir. Bu açıdan eksik bilgiden kaynaklanan belirsizliğin hakim olduğu prototip üretiminde Gri Hedef Programlama yaklaşımının kullanılması uygun olmaktadır. Bu çalışmada otomotiv sektöründe faaliyet göstermekte olan bir işletmenin prototip üretiminde karşılaştığı işgücü çizelgeleme karar problemi incelenmiştir. İşletmeden alınan gerçek verilerle oluşturulan model Excel Solver yardımıyla çözülmüştür.
\end{abstract}

Anahtar Kelimeler: Hedef Programlama, İşgücü Çizelgeleme, Gri Sistem Teorisi, Gri Hedef Programlama, Çok Amaçlı Karar Verme

JEL Sinıflandırması: C61, D8, E23

Abstract

Solution of Labor Scheduling Decision Problems with Grey Goal Programming ${ }^{2}$

Labor scheduling decision problems are a difficult and time-consuming problem to be solved by businesses working on shift and irregular working days. It is inevitable for businesses to make decisions under uncertainty when we consider today's competition conditions. Grey system theory includes methods used in modeling uncertainty caused by incomplete information. Goal Programming method provides satisfactory solutions to minimize deviations from goals set within constraints that limit decision problem. Labor scheduling decision problem is a decision problem that decision maker has more than one goal. In this respect, it is appropriate to use Grey Goal Programming approach in production of prototypes where uncertainty caused from incomplete information is dominant. In this study, labor scheduling decision problem with prototype production has been examined in a business that operates in automotive sector. Model has been solved by help of Microsoft Excel Solver using real data derived from business.

Keywords: Goal Programming, Labor Scheduling, Grey System Theory, Grey Goal Programming, Multiobjective Decision Making

JEL Classification: C61, D8, E23

${ }^{1} \mathrm{Bu}$ çalışma, yazarlardan Doç. Dr. Aslı ÖZDEMİR' in tez danışmanlığında diğer yazar Gülper BASMACI'nın hazırlamış olduğu "Gri Hedef Programlama ve Yöntemin Prototip Üretiminde İşgücü Çizelgeleme Karar Problemine Uygulanması" başlıklı yüksek lisans tezinin bir bölümüne dayanmaktadır

2 Extended abstract is presented at the end of the article.

Geliş Tarihi (Received): 02.08.2019 - Kabul Edilme Tarihi (Accepted): 30.12.2019

Atıfta bulunmak için/Cite this paper:

Basmac1, G. ve Özdemir, A. (2019). Gri hedef programlama ile işgücü çizelgeleme karar problemlerinin çözümü. Çankırı Karatekin Üniversitesi İIBF Dergisi, 9 (2), 559-591. 


\section{Giriş}

Birçok gerçek dünya karar probleminde birden fazla, muhtemelen birbirleri ile çelişen, amaçlar bulunmaktadır. Örneğin karar verici otomobil seçiminde araç güvenliğini maksimize etmeye çalışırken, yakıt ve satın alma maliyetini minimize etmeye çalışabilmektedir. Ya da örneğin tıp alanında tedavinin başarı olasılığı maksimize edilmeye çalışırken tedavinin süresi ve yan etkileri minimize edilmeye çalışılmaktadır. Bu tip durumlar karar teorisinde çok amaçlı karar verme yöntemlerinin doğuşuna sebep olmuştur (Roijers ve Whiteson, 2017, s. 8).

Çok amaçlı karar verme yöntemlerinden biri olan hedef programlama, organizasyonlarda ve toplumda karşılaşılan karar verme problemlerine yönelik olarak tasarlanmış ve oldukça çok kabul görmüş bir çeşit Doğrusal Programlama tabanlı karar verme tekniğidir. Hedef kısitları olmadan Doğrusal Programlama modelleri yalnızca karın en büyüklenmesi ya da maliyetin en küçüklenmesi gibi tek bir amaca odaklanırken, hedef programlama birbiriyle çelişen çok sayıda hedefi bu hedeflerden istenmeyen sapmaları minimize etme biçiminde amaçsallaştırarak optimize etmeye çalışmaktadır. Bu sebeple hedef programlama, salt optimizasyon aracı değil aynı zamanda tatmin aracıdır. $\mathrm{Bu}$ sebeple de Doğrusal Programlama modellerinde "optimal" çözüm olarak adlandırılan nihai çözüm değeri hedef programlama modellerinde "tatmin edici çözüm" olarak da adlandırılmaktadır (Hemaida ve Hupfer, 1995, s. 25).

Belirsiz yapılı iç ve dış çevre koşulları işletmelerin karar süreçlerinin pek çoğunun belirsizlik ortamında gerçekleşmesine neden olmaktadır. Gerçek dünya karar problemlerinde; işletmeler, verecekleri karara ilişkin yeterli bilgiye nadiren sahiptir. $\mathrm{Bu}$ durum, karar problemlerinin çözümünün belirsizliği modelleyen yöntemlerle birlikte yapılmasını gerektirmektedir. Karar problemlerinin belirsizlikle birlikte ele alınması modelin başarısını arttıran bir unsurdur.

Literatürde belirsizliği modellemek üzere en sık karşılaşılan üç farklı belirsizlik türünden bahsetmek mümkündür. Bunlar; stokastik belirsizlik, bulanık belirsizlik ve gri belirsizlik şeklinde siralanmaktadır. Stokastik ve bulanık belirsizliğin modelleyemeyeceği kadar sınırlı sayıda verinin bulunduğu durumlarda karşılaşılan belirsizlik türü gri belirsizliktir. Gri belirsizliğin temel kaynağı bilginin yetersizliğidir. Kesin değerlerdeki eksiklik nedeniyle gri belirsizlik ortaya çıkmaktadır (Papageorgiou ve Salmeron, 2012, s. 55). Gri Sistem Teorisi'nin odak noktası küçük örneklerle çalışılan karar problemlerinde karşı karşıya kalınan belirsizlik durumudur. Az veri sayısı ile çalışılan karar problemlerinde karşılaşılan belirsizliğin diğer teoriler vasıtasıyla işlenmesi zordur ya da mümkün değildir. $\mathrm{Bu}$ sebeple karar problemlerinin modellenmesinde güçlük çekilen bu noktayı Gri Sistem Teorisi kapatmaktadır (Liu, Fang, Yang ve Forest, 2012, s. 102).

Doğrusal Programlama esas olarak, karar probleminin çözümünü olası en uygun hale getirme amacının nasıl garanti altına alınacağı konusunda belirli kısıtlamalar ile 
çalışmaktadır. Bu problemlerde, kısıtlama koşulu ve amaç fonksiyonu doğrusal ise, problemlere Doğrusal Programlama problemleri denmektedir. Doğrusal Programlama, geniş bir yelpazede hızlı gelişen uygulamalı araştırmaların en önemli dallarından birisidir (Liu ve Dang, 2009, s. 751). Gri Sistem Teorisi'nin fikir ve modelleme yöntemini kullanarak oluşturulacak olan Doğrusal Programlama modeli Gri Doğrusal Programlama modeli olarak adlandırılmaktadır (Liu ve Lin, 2006, s. 369). Gri Hedef Programlama yöntemi ise Doğrusal Programlama tabanı ile gri sayılardan ve gri matematikten yararlanarak hedeflerden istenmeyen sapmaların minimizasyonu amacını taşımakta olan bir belirsizlik altında çok amaçlı karar verme yöntemidir.

İşletmeler, hayati faaliyetlerini sürdüren bir çeşit yaşayan organizmalardır. Bir yandan yaşamsal faaliyetlerini sürdürürken, diğer yandan bu faaliyetlerin bir sonucu olarak çeşitli maliyetlere katlanmaktadırlar. Katlandıkları bu maliyetler arasında en önemlilerinden biri işgücü maliyetidir. İşgücü maliyeti, işletmelerin pazarda rekabet güçlerinden biri olan üretim maliyet kalemi içerisinde önemli bir yer tutmaktadır. Bu sebeple günümüzde var olan yoğun rekabet koşullarında pek çok işletme üretim maliyetlerini minimize etmek amacıyla işgücü maliyetlerini düşürmeye çalışmaktadır. $\mathrm{Bu}$ noktada işletmelerin karşısına işgücü çizelgeleme karar problemleri çıkmaktadır. Kantitatif yöntemler kullanılarak yapılan başarılı işgücü çizelgelemesi işletmelerin maliyetlerini düşüren, üretim performanslarını ve çalışan memnuniyetini arttıran, planlama sorunlarını ortadan kaldıran yönetimsel bir araçtır.

İşgücü çizelgeleme, üretim ve hizmet sektöründe düzenli olarak karşılaşılan karar verme süreçlerinden birisidir. Buna göre işgücünün çizelgelenmesi belirli bir işin yapılabilmesi için minimum işgücü kullanımını sağlayacak çizelgenin belirlenmesi işidir. Bir iş yerinde belirli bir zaman aralığında, belirli bir işin yapılabilmesi için çalıştırılması gereken minimum işçi sayısına göre hazırlanmış çalışma planının belirlenmesidir (Bechtold ve Jacobs, 1990, s. 591). Amac1 en az personelin çalıştırılması ile ulaşılmak istenen hedeflerin sağlanmasıdır. $\mathrm{Bu}$ yapılırken personelin memnuniyeti işletmeler tarafından göz önünde bulundurulmalıdır.

$\mathrm{Bu}$ çalışmada otomotiv sektöründe faaliyet göstermekte olan çok uluslu bir işletmenin prototip departmanında, prototip üretimi esnasında karşılaşılan işgücü çizelgeleme karar problemi ele alınmıştır. İşletmenin çizelgeleme yaparken ulaşmak istediği birden fazla hedefi bulunmaktadır. $\mathrm{Bu}$ hedefler belirlenen üretim miktarından daha az üretim yapılmamasını ve belirlenen akşam vardiyası bütçesinin aşılmamasını içermektedir. Aynı zamanda uygulamanın yapıldı̆̆ departmanının çalışma prensibi gereği işgücü çizelgeleme karar problemi eksik bilgiden kaynaklanan belirsizliğin etkisi altındadır. Bu sebeple çözüm yöntemi olarak Gri Hedef Programlama Yöntemi seçilmiştir. 


\section{Literatür Taraması}

Hedef Programlama'nın kavramsal olarak kullanımının ilk izleri Romero'nun 1991 yılında yazdığı "Handbook of Critical Issues in Goal Programming" adlı kitaba göre Charnes, Cooper ve Ferguson'un 1955 yılında yazdığı firsat maliyeti kavramını içeren makalede rastlanmaktadır. 1955 yılında yazılmış olan bu makalede Hedef Programlama ifadesi kullanılmamış, fakat onun yerine hedef programlanın özünü oluşturan sapmaları minimize eden bir çeşit kısıtlı regresyon yaklaşımdan bahsedilmiştir. Romero’ya göre Charnes ve Cooper'ın 1961 yılında yazdıkları "Management Models and Industrial Applications of Linear Programming" kitabına kadar Hedef Programlama kavramına literatürde hiç rastlanmamıştır. Şaşırtıcı bir biçimde yöntemin adının ilk kez konulduğu bu çalışmada Hedef Programlanma'dan eşsiz ya da devrimsel bir yöntem olarak bahsedilmemiş, yalnızca "Doğrusal Programlama'nın bir çeşit uzantısı" olarak söz edilmiştir. Charnes ve Cooper'a göre yöntem özel değildir ve yazarlar tarafından yöntemin Doğrusal Programlama'nın çözemediği, olursuz problemlerde kullanılması önerilmiştir. Kısacası Hedef Programlama'nın önemi, literatürde doldurduğu boşluk ve kullanım alanları ortaya atıldığ 1 yıllarda anlaşılamamış, hatta ilk kez kavramın kullanıldığ 1961 yılındaki bu kitapta kavramın literatür için katkısı ön görülemediğinden indeks bölümünde terim olarak eklenmesi dahi atlanmıştır. 1965 yılında Ijiri çalışmasında Hedef Programlama yöntemine yer vermiştir. Çalışmada Hedef Programlama'dan çoklu çatışan amaçlara sahip karar problemleri ile başa çıkabilen bir yöntem olarak bahsedilmektedir. Çalışmada, Hedef Programlama'nın Doğrusal Programlama'dan farklı bir yöntem olduğu ve bu ayrımın da Hedef Programlama'nın sahip olduğu hedeflerden sapmaların minimize edilmesi amacından kaynaklandığı bilgisine yer verilmektedir. Yöntem 1977 yılında Charnes ve Cooper tarafından geliştirilmiştir.

Hedef Programlama'nın ulusal ve uluslararası yazında işletme uygulaması olan pek çok yayın bulunmaktadır. Buffa ve Jacson (1983) fiyat, kalite ve teslimat hedeflerini kullandığ 1 bir çalışma yapmıştır. Lee ve Kim (2000) uçak kontrol grubu seçimi karar probleminde yöntemi uygulamıştır. Atmaca (2002), üretim planlama karar problemini Hedef Programlama modeli ile çözdüğü çalışmasını yayınlamıştır. Leung ve diğerleri (2000), yine Hedef Programlama modelini üretim planlama karar probleminin optimizasyonu amacıyla kullanmıştır. Mendoza ve diğerleri (2008), AHP ve Hedef Programlama metotlarını sipariş atamalarının çok amaçlı olarak en iyilenmesi amacıyla kullanmıştır. Paksoy ve Chang (2010) tedarik zinciri yönetiminde 0-1 Tamsayılı Hedef Programlama modelini uygulamıştır. Akdeniz ve Aras (2010), Bulanık Hedef Programlama yaklaşımı ile İzmir'deki bir plastik işletmesinin stratejik hedeflerini konu almış ve çalışmalarında toplamsal Hedef Programlama yaklaşımını kullanmıştır. Karaman ve Çerçioğlu (2015) hastane yatırım projesi seçiminde 0-1 Hedef Programlama yöntemini kullanmıştır.

Gri sistemlerin temelini oluşturan gri sayıların üzerine kurulu olduğu aralık sayıları kavramı Young'un 1931 yılında yaptığı "The Algebra of Many-Valued Quantities" adlı makaleye dayanmaktadır. Bu çalışmayı Moore'un 1979 yılında aralık sayıların 
uygulanmasını incelediği çalışma izlemiştir. Aralık matematiği ile Doğrusal Programlama Tabanlı Optimizasyon Uygulamaları'nın yapıldığı ilk çalışma Ishihuchi ve Tanaka tarafindan 1990 yllında "Multiobjective Programming in Optimization of The Interval Objective Function" adlı makaledir.

Gri Sistem Teorisi ise 1980'li yıllarda geliştirilmiştir. 1982'de Çinli bir araştırmacı olan Profesör Deng Julong (1982), karar vericiler veya araştırmacılar tarafindan elde edilen bilgilerin kısmen bilinmeyen, belirsiz veya eksik olabileceği varsayımı altında Gri Sistem Teorisi'ni ortaya atmıştır. "Control Problems of Grey Systems" adlı bu makale, Gri Sistem Teorisi'nin kavramsal olarak tanıtıldığı ilk makale olma özelliği taşımaktadır. Aynı yıl Deng tarafından "The Grey Control System” adlı çalışmanın da yayınlanmasıyla konu bilim dünyasının ilgisini iyice çekmeye başlamıştır.

Gri Sistem Teorisi'ne olan ilgi işletmecilik alanında da görülmektedir. Literatürde Gri Sistem Teorisi'nin işletmecilik alanında kullanıldığı pek çok çalışma mevcuttur. Yao ve diğerleri 2003 yılında işletmelerde enerji maliyetini düşürmek amacıyla gri tahminleme modeli oluşturmuştur. Böylece elektrik ihtiyacına kısa dönemli tahminler yapılarak yüksek enerji tüketimine sahip işletmeler için maliyeti düşürme etkisi olan sonuçlar elde edilmiştir. Tseng'in 2009 yılındaki çalışmasının amacı en iyi beklenen hizmet kalitesi aracını seçmektir. Çalışmada Gri Tabanlı DEMATEL yöntemine başvurulmuştur. Özdemir ve Deste 2009 yılındaki makalelerinde otomotiv sektöründe tedarikçi seçimi karar probleminde Gri İlişkisel Analiz kullanmıştır. Kayacan ve Okyay 2010 yılında Euro-Dolar paritesinde Zaman Serisi Tabanlı Gri Tahminleme yöntemini kullanmıştır. Askari ve Askari 2011 yılında yayınlamış oldukları makalelerinde gri tahminleme yöntemini zaman serilerine uygulayarak altın fiyatlarını tahminlemek amacıyla kullanmıştır. Ayrıca Wang ve diğerleri 2012 yılındaki çalışmalarında süreç yeterlilik indeksi ve gri tahminlemeden oluşan hibrit bir yöntem sunmuştur. Köse ve diğerleri 2011 yılındaki çalışmalarında ekonomik sipariş miktarının belirlenmesi karar modeline Gri Sistem Teorisi ile yaklaşmıştır. Rahimnia ve Moghadasian 2011 yılında yaptıkları çalışmada Gri Sistem Teorisi'ni organizasyonel vizyonun ölçümlenmesi amacıyla kullanmıştır. Hamzaçebi ve Pekkaya 2011 yılında hisse senedi seçiminde Gri İlişkisel Analiz yöntemini kullanmıştır. Liu ve diğerleri 2011 yılında ise, hata türü ve etkileri analizinde Gri Sistem Teorisi'ne başvurmuştur. 2014 y1lında Xia ve Wong moda perakendeciliği için mevsimlik ayrık Gri Tahmin Modeli'ni sunmuştur. Rajesh ve Ravi 2015 yılında yapmış oldukları çalışmalarında dayanıklı tüketim malları için tedarikçi seçiminde Gri İlişkisel Analiz’e başvurmuştur. Özdemir ve Özdağoğlu 2017 y1lında talep tahminlemesi karar probleminin çözümünde Markov Zinciri Entegre Gri Model kullanmıştır. Hsiao ve diğerleri 2017 yılında ürün geliştirme sürecindeki karar problemlerinde Gri İlişkisel Analiz kullanmıştır. Balderas ve diğerleri 2018 yılında yapmış oldukları çalışmalarında proje portföyü seçiminde Gri Tabanlı Çok Amaçlı Karar Verme Yöntemleri'nden yararlanmıştır. 2018 yılında $\mathrm{Hu}$ ve diğerleri, Yapay Sinir Ağları ve Gri Markov Yöntemi'ni birlikte kullanarak 
turizm ihtiyacını tahminlemişlerdir. Çelikbilek 2018 yılında Gri Analitik Ağ Süreci yardımıyla proje yöneticisinin seçilmesi karar problemini çalışmıştır.

İşgücü çizelgelemesi yazınının ilk çalışması 1954 yılında Edie tarafından yapıllmış olan trafik geçişlerinin incelendiği ve ihtiyaç duyulan personelin saptanması amacıyla sabit kuyruk sisteminin oluşturulduğu çalışmadır. İşgücü çizelgeleme karar problemleri üzerine yapılmış ikinci çalışma Dantzig tarafından 1954 yılında vardiya çizelgelemek amacıyla yapılmıştır. Dantzig tarafından önerilmiş olan bu model uzun yıllar işgücü çizelgelemesi konusunda referans alınan tek çalışma olmuştur. Bu süre yaklaşık kırk yıllık zaman periyodunu kapsamaktadır. Daha sonra işgücünün çizelgelenmesi konusunda hakim olan, personelin tercihlerine göre oluşturulmuş işgücünün ve işin farklı özelliklerine göre yeniden yapılandırılan modeller kurulması gerektiği düşüncesi ile konuya farklı bakış açılarına sahip çalışmalar yapılmaya başlanmıştır (Aykin, 2000, ss. 381-397).

Huarng (1999), 13 hemşirenin çalıştı̆ğ bir birim için 0-1 tamsayılı doğrusal Hedef Programlama modeli ortaya koymuştur. Çalışmada gündüz, akşam ve gece olmak üzere üç vardiya bulunmaktadır ve kıdemli hemşirelere zorunlu olmadıkça fazla mesai verilmemesine dikkat edilecek biçimde model oluşturulmuştur. Azaizez ve Sharif (2005), Suudi Arabistan'da Riyadh Al-Kharj Hastanesi'nde hemşire çizelgelemesi karar probleminde çözüm yöntemi olarak 0-1 tamsayılı Hedef Programlama metodunu kullanmıştır. Topaloğlu 2006 yılındaki çalışmasında ilaç dağıtan personel için işgücü çizelgelemesi yapmıştır. Çalışma, aylık tur planlama olarak düşünülmüş ve bir Hedef Programlama modeli ortaya konulmuştur. Mathirajan ve Ramamathan (2007), Hindistan'da büyük bir elektronik pazarlama şirketinde tur çizelgeleme problemini incelemişlerdir. Bu çalışmada yöntem olarak 0-1 tamsayılı Hedef Programlama yöntemi kullanılmıştır. Chu (2007), Hong Kong Uluslararası Havaalanında bagaj servisi için personel seçimi, mürettebat görevlerinin ataması problemini bütünleştiren bir Hedef Programlama modeli ortaya koymuştur.

Gri Doğrusal Programlama literatürde çok az çalışmada kendisine yer bulmuştur. Yapılan çalışmalar daha çok Gri Doğrusal Programlama'nın; Doğrusal Programlama'nın özel bir formu olması niteliğine sahip yöntemlerle hibrit çözümler sunulması şeklindedir. 2015 yılında Girginer ve Uçkun çalışmalarında Gri Doğrusal Programlama'yı veri zarflama analizinde kullanmıştır. Yöntemin diğer bir hibrit uygulama alanını ise Hedef Programlama entegrasyonu oluşturmaktadır.

Sadeghieh ve diğerleri 2012 yılındaki çalışmalarında Gri Hedef Programlama'yı genetik algoritma vasıtasıyla çözerek tedarikçi değerlendirme ve tedarikçi seçme karar problemine yeni bir yaklaşım sunmuştur. Yöntemin modellenmesinde gri amaç ağırlıkları skalası kullanılmıştır. Memon ve diğerleri 2014 yılında yapmış oldukları çalışmalarında tedarikçi seçiminde ürün güvenliği riskini yönetme konusuna Gri Hedef Programlama Tabanlı Karar Verme Yöntemi ile yaklaşmıştır. Tedarikçi seçiminde ürün güvenliği kriterini etkileyen faktörler olarak uygunluk, 
güvenilirlik, izlenebilirlik, kalite ve güvenlik standartları, depolama sistemi, lojistik sistemi, garanti politikası ve kontrat metodu kullanılmıştır. Karar vericinin tedarikçileri değerlendirmesi amacıyla kriterler gri amaç ağırlıkları skalasına göre değerlendirilmiş ve amaç fonksiyonu da bu kriterlerden sapmalar minimize edilecek biçimde oluşturulmuştur. Yöntemin çözümünde hangi Gri Doğrusal Programlama yaklaşımından faydalanıldığı bilgisi bulunmamaktadır. Fakat yöntemin çözümünde LINGO 14 paket programından yararlanıldığı belirtilmiştir. Sadeghi ve diğerleri 2013 yılında yapmış oldukları çalışmalarında aynı yöntemi bu kez bütünleşik üretim planlaması karar problemine uygulamıştır. Hajiagha ve arkadaşları 2014 yılındaki çalışmalarında gri sayılardan faydalanarak Bulanık Hedef Programlama yaklaşımı ile sürekli proje zamanı, maliyet ve kalite parametrelerini kullanarak proje yönetimi için hibrit model sunmuştur. Çalışmada gri sayılar kullanılmakla birlikte çözüm yöntemi olarak Bulanık Hedef Programlama yönteminden faydalanılmıştır. Mahdiraji ve diğerleri 2016 yılındaki makalelerinde zaman, maliyet, kalite ve risk parametreleri kullanılarak oluşturdukları Hedef Programlama modelleri ile bir projenin kritik yolunu belirlemeyi amaçlamıştır. Yöntemde parametreler beyazlaştırılmış, alt ve üst sınırlar için de çözüm gerçekleştirilerek gri sonuçlara ulaşılmıştır.

\section{Yöntem}

Bu başlık altında Hedef Programlama, Gri Doğrusal Programlama ve son olarak da Gri Hedef Programlama'nın matematiksel gösterimleri yer almaktadır.

\subsection{Hedef Programlama Yönteminin Genel Matematiksel Gösterimi}

Hedef Programlama'nın genel yaklaşımı, doğrusal programlamanın maksimizasyon ve minimizasyon mantığının üzerine hedef konulması ve bu hedeflerde ortaya çıkabilen istenmeyen sapmaların minimize edilmeye çalışılması üzerine kuruludur. Genel Hedef Programlama modellerinde $i=1,2, \ldots, m$ olmak üzere $m$ adet hedef kısıtı bulunmaktadır. Aynı zamanda modelde $x$ karar değişkeni olarak tanımlanmak üzere $j=1,2, \ldots, n$ adet karar değişkeni tanımlanmaktadır. Hedefler modelde karar vericinin üzerinde kontrol gücünün olduğu, çözülecek karar sorununa uygun olarak tanımlayabildiği faktörlerdir. Her hedefin bir $f_{i}(x)$ fonksiyonu vardır. $\mathrm{Bu}$ fonksiyon karar değişkenlerine bağlı olarak çalışmaktadır. Karar vericiler her hedef için $b_{i}$ olarak gösterilen sayısal bir hedef belirlemektedir. $\mathrm{Bu}$ da hedefin temel formülasyonunu oluşturmaktadır. Böylece $d_{i}^{-}$hedeften negatif sapmaları $d_{i}^{+}$ise hedeften pozitif sapmaları temsil etmektedir.

Hedef Programlama'da istenmeyen sapmalar hem pozitif yönlü, hem de negatif yönlü; yani hedefin üstünde gerçekleşen ya da hedefin altında gerçekleşen sapmalar biçiminde olabilmektedir (Sinha ve Sen, 2011, s. 1411). Sapma türleri ile hedefler arasındaki ilişki Tablo 1'de özetlenmiştir. 
Tablo 1: Hedef - İstenmeyen Sapma İlişkisi

\begin{tabular}{|c|c|}
\hline Hedef Tipi & Istenmeyen Sapmalar \\
\hline Tip 1: $\boldsymbol{a}_{\boldsymbol{i}} \boldsymbol{x}_{\boldsymbol{j}} \leq \boldsymbol{b}_{\boldsymbol{i}}$ & $d_{i}^{+}$ \\
\hline Tip 2: $\boldsymbol{a}_{\boldsymbol{i}} \boldsymbol{x}_{\boldsymbol{j}} \geq \boldsymbol{b}_{\boldsymbol{i}}$ & $d_{i}^{-}$ \\
\hline Tip 3: $\boldsymbol{a}_{\boldsymbol{i}} \boldsymbol{x}_{\boldsymbol{j}}=\boldsymbol{b}_{\boldsymbol{i}}$ & $d_{i}^{-}+d_{i}^{+}$ \\
\hline
\end{tabular}

Kaynak: (Jones ve Tamiz, 2010, ss. 12; Orumie ve Ebong, 2014, s. 61)

Tip 1 hedefler maliyetler gibi pozitif sapmaların cezalandırıldı̆̆ etmektedir. Bu tip hedeflerde pozitif sapma olması istenen bir durum değildir. Tip 2 olarak adlandırılan hedefler ise kar gibi negatif sapmaların cezalandırıldığ 1 hedeflerdir. Bu hedeflerden negatif sapmalar istenmemektedir. Tip 3 hedefler ise işgücü gibi negatif ve pozitif sapmaların her ikisinin de arzu edilmediği hedeflerdir. Hedefler kümesi bazı durumlarda "esnek kısıtlamalar" olarak adlandırılmaktadırlar. $\mathrm{Bu}$ isimlendirmenin yapılmış olmasının sebebi karar vericinin belirlemiş olduğu her hedefe sapmasız ulaşmak istemesi, fakat bunun mümkün olmaması halinde olurlu çözümün olmadığı anlamına gelmemesidir. Bu durumun bir sonucu olarak da elde edilecek çözüm optimal olmaktan ziyade, tatmin edici olacaktır (Jones ve Tamiz, 2010, ss. $11-12)$.

Yöntem Modelin amaç fonksiyonu, yaşanması arzu edilmeyen sapmaların bir araya getirilerek minimize edilmesi ile oluşturulmaktadır. Bu yapılan işlem ile amaç, istenmeyen sapmaları en aza indirmek ve böylece istenen hedefler kümesine "mümkün olduğu kadar yakın" bir çözüm bulunmasını sağlamaktır. Bunun için de karar vericinin hedeflerini önceliklendirmesi ve sıralaması gerekmektedir Öncelikler $p_{i}$ ile gösterilmektedir Hedefleri sıralamak için ise formülasyonda $w_{i}$ ile gösterilen ağırlıklardan da yararlanılmaktadır. Modeldeki pozitiflik koşulu ile de değişkenlerinin asla negatif değerler almaması sağlanmaktadır. (Jones ve Tamiz, 2010, ss. 12; Orumie ve Ebong, 2014, s. 61):

$$
\begin{gathered}
\operatorname{Min} z=\sum_{i}^{m} w_{i} p_{i}\left(d^{-}+d^{+}\right) \\
\sum_{j}^{n} a_{i j} x_{i j}+d^{-}-d^{+}=b_{i} \\
i=1,2, \ldots, m \\
j=1,2, \ldots, n \\
x \in F \\
x_{i j}, d^{-}, d^{+} \geq 0 \\
w_{i}>0
\end{gathered}
$$

Hedef Programlama'nın temel gösterimi 1965 yılında Ijiri'nin çalışmasında yer alan modeldir. Yöntem 1977 yılında, Charnes ve Cooper tarafından ağırlık ve öncelik faktörleri eklenerek düzenlenmiştir. Yukarıda tanımlanmış olan ağırlıklı ve öncelik 
faktörlerini de içeren Doğrusal Programlama Modeli tabanlı matematiksel gösterim Kwaks ve Schniederjans'ın 1982 yılındaki çalışmalarında literatürde en çok kullanılan gösterim olması sebebiyle Hedef Programlama'nın genel matematiksel gösterimi olarak adlandırılmıştır (Kwak ve Schniederjans, 1982, s. 859):

Literatürde Hedef Programlama'nın genel matematiksel formülasyonunu tanımlamada kullanılan geleneksel gösterimin yanı sıra Ignizio 1976 yılında karar problemlerinin pratikte temsilini sağlayan aşağıdaki matematiksel modeli ortaya koymuştur (Ignizio, 1976, s. 1112):

$$
\begin{gathered}
\operatorname{Min} \bar{a}=\left\{g_{1}(\bar{n}, \bar{p}), g_{2}(\bar{n}, \bar{p}), \ldots, g_{k}(\bar{n}, \bar{p})\right\} \\
f_{i}(\bar{x})+n_{i}-p_{i}=b_{i} \\
i=1,2, \ldots, m \\
\bar{x}, \bar{n}, \bar{p} \geq 0 \\
x \in F
\end{gathered}
$$

Bu modelde $\overline{\mathrm{x}}=\mathrm{x}_{1}, \mathrm{x}_{2}, \ldots, \mathrm{x}_{\mathrm{j}}$ olmak üzere $x_{j} j$. karar değişkenini ifade etmektedir. $\bar{a}$ amaç fonksiyonudur. $g_{k}(\bar{n}, \bar{p}) k$. seviye öncelikte hedeften $\bar{n}$ negatif sapma veya $\bar{p}$ pozitif sapma durumunu ölçen doğrusal fonksiyondur. Modelde $k$ adet öncelik seviyesi bulunmaktadır. $b_{i}$ hedef kısıtının sağ tarafını ifade etmektedir. $f_{i}(\bar{x})$ ise hedef kısıtının doğrusal ya da doğrusal olmayan, $n_{i} i$. hedeften negatif sapma durumunu $p_{\mathrm{i}}$ ise $i$. hedeften yaşanan pozitif sapmayı sembolize etmek üzere karar değişkenlerine bağlı fonksiyonudur (Ignizio, 1976, s. 1112).

\subsection{Gri Doğrusal Programlamanın Genel Matematiksel Gösterimi}

Gri Sistem Teorisi'nin fikir ve modelleme yöntemini kullanarak oluşturulacak olan doğrusal programlama modeli Gri Doğrusal Programlama modeli olarak adlandırılmaktadır (Liu ve Lin, 2006, s. 369). Gri Doğrusal Programlama'nın gösterimi $X(\otimes)$ modelin çözüm vektörü, $C(\otimes)$ amaç fonksiyonu katsayıları, $b_{i}(\otimes)$ kısıtların sağ tarafı ve $a_{i j}(\otimes)$ değişkenlerin kısıtlardaki kaynak kullanımı olmak üzere aşağıdaki gibidir (Liu ve Dang, 2009, s. 751):

$$
\begin{gathered}
X(\otimes)=\left[x_{1}(\otimes), x_{2}(\otimes), \ldots, x_{n}(\otimes)\right]^{T} \\
b(\otimes)=\left[c_{1}(\otimes), c_{2}(\otimes), \ldots, c_{n}(\otimes)\right] \\
A(\otimes)=\left[\begin{array}{llll}
\left.b_{1}(\otimes), b_{2}(\otimes), \ldots, b_{m}(\otimes)\right]^{T} \\
a_{11}(\otimes) & a_{12}(\otimes) & \ldots & a_{1 n}(\otimes) \\
a_{21}(\otimes) & a_{22}(\otimes) & \ldots & a_{2 n}(\otimes) \\
\ldots & \ldots & \ldots & \ldots \\
a_{m 1}(\otimes) & a_{m 2}(\otimes) & \ldots & a_{m n}(\otimes)
\end{array}\right]
\end{gathered}
$$

Kullanılan parametrelerin aralıksal gri sayı olarak gösterimi ve küme kapsamları aşağıdaki şekildedir: 


$$
\begin{gathered}
c_{j}(\otimes) \in\left[\underline{c}_{j}, \bar{c}_{j}\right], \underline{c}_{j} \geq 0, j=1,2, \ldots n ; \\
b_{i}(\otimes) \in\left[\underline{b}_{i}, \bar{b}_{i}\right], \underline{b}_{i} \geq 0, i=1,2, \ldots m ; \\
a_{i j}(\otimes) \in\left[\underline{a}_{i j}, \bar{b}_{i}\right], \underline{b}_{i} \geq 0, i=1,2, \ldots m .
\end{gathered}
$$

Sonuç olarak Gri Doğrusal Programlama'nın genelleştirilmiş gösterimi aşağı̀daki biçimde ifade edilmektedir (Hajiagha, Akrami ve Hashemi, 2012, s. 269):

$$
\max (\min ) \otimes C X \text { S.T. } \otimes A \otimes X\left(\begin{array}{l}
\leq \\
= \\
\geq
\end{array}\right) \otimes b \quad \otimes X \geq 0
$$

Literatürde üç farklı Gri Doğrusal Programlama çözüm yöntemine rastlanmaktadır. $\mathrm{Bu}$ yöntemler alt başlıklar halinde ele alınacaktır.

\subsubsection{Gri Doğrusal Programlama'nın Konumlandırılmış Çözümü}

Yöntemden ilk olarak Julong Deng'in yazdığı ve China Ocean Press tarafından 1988 yllında yayınlanmış olan Grey System adlı kitapta, "Grey Linear Programming" bölümünde gri parametrelerin kullanıldığ Gri Doğrusal Programlama modelinde bahsedilmiştir. Deng'in sunduğu gri parametreli doğrusal programlama modeli üzerine yazılmış olan "New Study on The Solution of Grey Linear Programming" adlı çalışma 1997 yılında Weaping Wang tarafından yayınlanmıştır. Deng'in ortaya koyduğu yöntemin üzerine Xiao 1998 yılında iyileştirmeler yaparak Journal of Grey System adlı dergide yayınlamıştır. (Deng, 1988, ss. 130-138; Wenping, 1997, ss. 41-46; Xinping, 1998, ss. 133-139). Yöntemin literatürdeki son ve en kapsamlı hali Sifeng Liu'nun 2006 yılında yayınladığı "Grey Information Theory and Practical Applications" kitabında bölüm olmuş; daha sonraları Sifeng Liu ve Yaoguo Dang tarafindan 2009 yılında San Antonio'da yapılmış konferansta sunulmuştur. Bu başlık altında gri parametrelerle doğrusal programlama Sifeng Liu ve Yaoguo Dang'in ortaya koyduğu biçimde "Doğrusal Programlamanın Konumlandırılmış Çözümü" adı altında açıklanacaktır (Liu ve Lin, 2006, ss. 367-377; Liu ve Dang, 2009, ss. 751- 756).

Doğrusal programlamanın konumlandırılmış çözümü (On Positioned Solution of Grey Linear Programming) gri parametrelerin kullanıldığı bir doğrusal programlama modeli çeşididir. Yöntemin temelleri gri parametrelere sahip doğrusal programlama yönteminin beyazlaştırma işlemine tabi tutularak geleneksel doğrusal programlama yöntemine benzetilmesi üzerine kurulmaktadır. Yöntemin en önemli avantaj1 uygulamasının kolay ve hızlı oluşudur (Liu ve Lin, 2006, ss. 367-377; Liu ve Dang, 2009, ss. 751-756).

Yöntemin bir diğer adı da "Sürüklenen (drifting) Gri Doğrusal Programlama"dır. Çözüm sonunda gri çözüm vektörü elde edilmemekte, ancak farklı beyazlaştırma fonksiyonları kullanılarak tatmin derecesine göre çözüm değerlerinin hesaplanması ile, karar vericinin tercih edeceği gri çözüm aralıkları saptanabilmektedir. Yöntemde "sürüklenen" ifadesinin kullanılış sebebi çözüm sürecinin birbirini izleyen bir dizi 
doğrusal programlama setinden oluşmasıdır. Yöntemde optimal çözüme ulaşılamamakta, bunun yerine tatmin edici çözüme ulaşılmaktadır (Liu ve Lin, 2006, ss. 367-377; Liu ve Dang, 2009, ss. 751-756).

Yöntemde $\tilde{C}(\otimes), \quad \tilde{b}(\otimes), \tilde{A}(\otimes)$ Gri Doğrusal Programlama modelinin sirasiyla amaç fonksiyonu katsayısı, kısıtların sağ tarafı ve değişkenlerin kısıtlardan kaynak kullanımını göstermek üzere beyazlaştırılmış vektörleridir. Beyazlaştırma fonksiyonuna göre seçilmiş $\rho_{i}, \beta_{i}, \delta_{i j} \in[0,1], i=1,2, \ldots, m ; j=1,2, \ldots, n$. şeklinde tanımlanan $\rho_{i}, \beta_{i}, \delta_{i j}$ ise beyazlaştırma faktörleridir. Buna göre Gri Doğrusal Programlama modelinin beyaz parametreleri aşağıdaki biçimde hesaplanmaktadır:

$$
\begin{gathered}
\tilde{c}_{j}(\otimes)=\rho_{j} \bar{c}_{j}+\left(1-\rho_{j}\right) \underline{c}_{j} ; j=1,2, \ldots, n \\
\tilde{b}_{j}(\otimes)=\beta_{i} \bar{b}_{i}+\left(1-\beta_{i}\right) \underline{b}_{i} ; i=1,2, \ldots, m \\
\tilde{a}_{i j}(\otimes)=\delta_{i j} \bar{a}_{i j}+\left(1-\delta_{i}\right) \underline{a}_{i j} ; i=1,2, \ldots, m ; j=1,2, \ldots, n
\end{gathered}
$$

Oluşturulan doğrusal programlama modelinin çözümünde simpleks metodundan faydalanılmaktadır. Yöntemin çözümünde, kullanılacak beyazlaştırma faktörü önemli bir yer tutmaktadır. Kullanılan beyazlaştırma faktörüne göre yönteme üç farklı yaklaşımda bulunulabilmektedir:

- İdeal Model: Amacı kazancını maksimize etmek olan yukarıda açıklanmış etki durumları altındaki bir doğrusal programlama modelinde en ideal çözüme ulaşabilmek amacıyla $\rho=\beta=1, \delta=0$ beyazlaştırma faktörleri kullanılmakta, yani $L P(1,1,0)$ modeli kurulmaktadır. Bir başka deyişle aralıksal gri sayılar maksimizasyon amacı için en iyimser senaryoya göre beyazlaştırılmaktadırlar. $\mathrm{Bu}$ işlemin sonucunda beyazlaştırılmış parametrelerden oluşan Gri Doğrusal Programlama modeli çözüldüğünde max $\bar{S}$ 'ye, yani maksimizasyon amacı taşıyan doğrusal programlama modeli çözümünün üst sınırına ulaşılmaktadır.

- Kritik Model: Benzer biçimde en ideal olmayan çözüme ulaşabilmek amaciyla $\rho=\beta=0, \delta=1$ beyazlaştırma faktörleri kullanılmakta, yani $\operatorname{LP}(0,0,1)$ modeli kurulmaktadır. Bir başka deyişle aralıksal gri sayılar maksimizasyon amacı için en kötümser senaryoya göre beyazlaştırılmaktadır. $\mathrm{Bu}$ işlemin sonucunda beyazlaştırılmış parametrelerden oluşan Gri Doğrusal Programlama modeli çözüldüğünde max $\underline{S}$ 'ye, yani maksimizasyon amacı taşıyan doğrusal programlama modeli çözümünün alt sınırına ulaşılmaktadır.

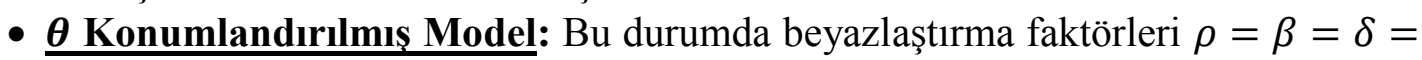
$\theta$ biçiminde kullanılmakta, yani $L P(\theta)$ modeli kurulmaktadır. Kurulmuş olan Gri Doğrusal Programlama modelinin çözümünden elde edilecek değer max $S(\theta)$ olmaktadır. Çözüm değerlerine " $\theta$ optimal çözüm değerleri" adı verilmektedir. $\theta$ değeri olarak çoğunlukla $\theta=0,5$ kullanılmaktadır. Bir başka deyişle eşit ağırlıklı ortalama beyazlaştırma $L P(\theta)$ modelinde en sık kullanılan değerdir. 
$\rho, \beta, \delta \in[0,1]$ olmak üzere $L P(\rho, \beta, \delta)$ modeli için konumlandırılmış Gri Doğrusal Programlama'nın tatmin derecesi aşağıdaki formülasyonla hesaplanmaktadır:

$$
\mu(\rho, \beta, \delta)=\frac{1}{2}\left(1-\frac{\max \underline{S}}{\max S(\rho, \beta, \delta)}\right)+\frac{1}{2}\left(1-\frac{\max S(\rho, \beta, \delta)}{\max \bar{S}}\right)
$$

Konumlandırılmış Gri Doğrusal Programlama'nın tatmin derecesi $L P(\theta)$ modellerinde ulaşılan max $S(\theta)$ değeri ile ideal model çözümü olan max $\bar{S}$ ve kritik model çözümü olan $\max \underline{S}$ arasındaki ilişkiyi yansıtmaktadır. $\max S(\theta)$ değeri max $\bar{S}$ 'ye yaklaştıkça $\mu(\rho, \beta, \delta)$ yükselmekte, $\max S(\theta)$ değeri max $\underline{S}$ 'ye yaklaştıkça ise $\mu(\rho, \beta, \delta)$ düşmektedir.

\subsubsection{Gri Doğrusal Programlama'da Kapsama Çözümü}

Gri Doğrusal Programlama'da kapsama çözümü 2007 yılında Qiao-Xing Li tarafindan "The Journal of Grey System" adlı dergide yayınlanan makale ile literatüre kazandırılmıştır. Makalenin orijinal adı "The Cover Solution of Grey Linear Programming”tir. Yöntemde kullanılan "kapsama" ifadesinin kökeni Gri Sistem'lerin aralık matematiğinden farklılıklarına dayanmaktadır. Aralık matematiğinde verilen aralıktaki tüm sayılar çözüm kümesini sağladığı için aralık biçiminde ifade edilirken, Gri Sistem Teorisi'nde yalnızca belirli aralıkta olduğu bilgisine sahip olunması fakat bu aralıkta yalnızca tek bir beyaz sayının olduğu düşüncesi Gri Sistem Teorisi'ndeki aralıksal sayıları, salt aralıksal ifadelerden ayırmaktadır. Bu noktada "kapsama" kavramı devreye girmektedir. Gri Doğrusal Programlama modeli oluşturulurken eksik ve yetersiz bilgi sebebiyle tam olarak tespit edilemeyen beyaz sayıyı kapsayan bir aralık saptanmaya çalışılmaktadır ( $\mathrm{Li}$, 2007, ss. 309-320).

Genel doğrusal programlama modeline göre eksik veya yetersiz bilgi sebebiyle gri belirsizliğin etkisi altında modellenmeye çalışılan Gri Doğrusal Programlama modelinde parametreler gri sayı biçiminde $(i=1,2,3, \ldots m ; j=1,23, \ldots, n)$ olmak üzere $c_{j}(\otimes), b_{i}(\otimes)$ ve $a_{i j}(\otimes)$ biçiminde tanımlandığında genel Gri Doğrusal Programlama modeli aşağıdaki biçimi almaktadır:

$$
\begin{gathered}
\max z(\otimes)=C(\otimes) X \\
\{(\otimes) X=b(\otimes) \\
X \geq 0
\end{gathered}
$$

3.2.3. Gri Doğrusal Programlama'nın Çözümüne Çok Amaçlı Karar Verme Yaklaşımı

Gri Doğrusal Programlama'nın çözümüne çok amaçlı karar verme yaklaşımı, Gri Sistem yazınında Gri Doğrusal Programlama çözümüne dair yayınlanmış en yeni yaklaşımdır. 2012 yılında Hajiagha ve diğerleri tarafından çalışılmış ve "Grey Systems: Theory and Application" adlı dergide yayınlanmıştır. Yöntemin yalnızca 
amaç fonksiyonunda gri sayıların kullanıldığı, daha az kapsamlı hali 1990 yılında Ishibuchi ve Tanaka tarafından çalışılmıştır. Yöntem diğer Gri Doğrusal Programlama çözümü yöntemlerinin aksine modelin parametrelerinden herhangi birinin alt ve üst limitlerinin işaretlerinin farklı olması durumunda da kullanılabilmektedir. Bunun yanı sıra yöntem, diğer çözüm metotlarının aksine bir dizi model kurulumu ve çözümü gerektirmemektedir. Oluşturulan modelin çözümü ile çözüm değerleri de aralıksal gri sayı formunda elde edilmektedir. Bu bakımdan yöntemin matematiksel altyapısı uygulama kolaylığı sağlayacak basitliktedir ve uygulanması hızlıdır denilebilir. Yaklaşım esas olarak gri sayılar arasındaki düzen ve üstünlük ilişkilerine dayanmaktadır (Ishibuchi ve Tanaka, 1990, ss. 219-225).

\subsection{Gri Hedef Programlamanın Genel Matematiksel Gösterimi}

Gri Hedef Programlama yöntemi Hedef Programlama ile aynı formülasyonu kullanmaktadır. Yöntemin Hedef Programlama'dan ayrılan yönü parametrelerinin ve çözüm değerlerinin gri formda gösterilmesidir. Buna göre Gri Hedef Programlama yönteminin formülasyonu aşağıdaki biçimde ifade edilmektedir (Memon, Li, Mari ve Cho, 2014, s. 4):

$$
\begin{gathered}
\operatorname{Min} \otimes z=\sum_{i}^{m} \otimes w_{i} \otimes p_{i}\left(\otimes d^{-}+\otimes d^{+}\right) \\
\sum_{j}^{n} \otimes a_{i j} \otimes x_{i j}+\otimes d^{-}-\otimes d^{+}=\otimes b_{i} \\
i=1,2, \ldots, m \\
j=1,2, \ldots, n \\
\otimes x \in F \\
\otimes x_{\mathrm{ij}}, d^{-}, d^{+} \geq 0 \\
\otimes w_{i}>0
\end{gathered}
$$

Yayınlanmış Gri Hedef Programlama çalışmaları incelendiğinde ya yöntemin çözümünde kullanılan metodolojiye ilişkin çok az bilgi paylaşıldığı ya da doğrusal programlamanın bir uzantısı olarak değerlendirilip Gri Doğrusal Programlama yöntemi kullanılarak çözüldüğü görülmektedir.

\section{4. İşü̈cü Çizelgeleme Karar Problemlerinde Gri Hedef Programlama’nın Kullanılması}

$\mathrm{Bu}$ başlık altında ilk olarak uygulamanın yapıldığı işletmeye ilişkin bilgilere yer verilmektedir. Ardından ele alınan problemin tanımı yapılmakta, modellenmekte ve Gri Hedef Programlama yöntemine göre çözümü gerçekleştirilmektedir. 


\subsection{Karar Probleminin Tanımlanması}

Uygulamanın yapıldığı işletme otomotiv ve taşımacılık endüstrilerinde önemli işlere sahip olan ve telekomünikasyon, medikal, bilgisayar ve çevre birimleri de dahil olmak üzere diğer yüksek teknoloji endüstrilerinde büyüyen dünyanın önde gelen teknoloji şirketlerinden biridir. İşletmenin yazılım veya elektronik geliştirmeye adamış 16.000 mühendis, bilim adamı ve teknisyeni vardır. İşletme araştırma, geliştirme ve mühendislik konularında yılda yaklaşık 2 milyar dolar bütçe ayırmaktadır ve dünyada faaliyetlerini 34 ayrı merkezde yürütmektedir.

Uygulama, ele alınan işletmenin prototip departmanında gerçekleştirilmiştir. Prototip departmanının amacı müşterilerden nadiren gelen müşteri siparişlerinin üretimini gerçekleştirmektir. Prototip departmanında üretilen ürünlerin seri imalatta üretilmesi maliyetli olmaktadır. Bir ürünün seri imalatta üretilebilmesi için belirli bir miktarın üzerinde olması gerekmektedir. Kısa süreli ve düşük hacimlerde üretimi yapılması istenen ürünlerin imalatı için prototip departmanı tercih edilmektedir.

$\mathrm{Bu}$ çalışmada uygulamanın yapıldığı prototip departmanında 2 vardiyada üretim yapılmaktadır. Yapılan görüşmelerde departmana gelen iş emirlerinin kısa süreli ve düşük hacimli işleri içermesinin işgücünün çizelgelemesi bakımından zorluğa sebep olduğu görülmüştür. Aynı iş yılda en fazla $3 \mathrm{kez}$ departmana iş emri olarak gelmektedir. Bu sebeple prototip üretiminin çizelgelenmesi süreci, eksik verinin etkisi altında belirsiz yapılı bir süreçtir. Çalışanların üretimi yapılacak parçayı hangi sürelerde üretebildiği bilgisi ancak eğer mevcutsa aynı ürünün önceki üretim verilerinden alınmakta ya da benzer yapılı ürünlerin üretim verilerinden faydalanılarak tahmin edilmektedir. Yeterli verinin bulunmadığı bu uygulama ortamında üyelik fonksiyonunun saptanmasındaki güçlük ve olasılık dağılımının belirlenmesindeki zorluklar sebebiyle belirsizliğin modellenmesinde bulanık ve stokastik belirsizlik modelleme yöntemlerinin kullanılamayacağı, belirsizliği modellemek için en uygun belirsizlik çeşidinin gri belirsizlik olduğu sonucuna varılmıştır.

Departmanın işgücü çizelgelemesi konusundaki en büyük sorunlarından biri personellerin maaşları arasındaki farklılıktır. Çok uluslu yapıdaki bu işletmede bir dönem maaşların döviz ile verilmesi sonucunda, dövizle maaşı verilen dönemde işe başlamış olan personel ile sonradan çalışmaya başlayan personel arasında kurdaki değişiklikler sebebiyle aynı pozisyonda çalıştıkları halde ciddi farklılıklar doğmuştur. Bu durum sebebiyle işgücü çizelgelemesi yapılırken işletmenin amacı gelen iş emri sayısında ve zamanında üretim yapmak olduğu gibi aynı zamanda vardiya maliyetlerini de minimize etmektir.

Uygulama yapilan prototip departmanında 11 personel ve 11 adet tezgah bulunmaktadır. Departmanda 1. vardiya gündüz vardiyası olarak adlandırılmaktadır. 2. vardiyaya ise akşam vardiyası denilmektedir. Gündüz vardiyasında 11 personelin tamamı çalışırken, akşam vardiyasında işin durumuna göre departman üretim 
sorumlusunun sezgisel olarak seçtiği personeller nöbetçi bırakılmaktadır. Vardiyaya göre çalışma saatleri ile çay ve yemek molaları çıkarıldığında kalan çalışma süreleri aşağıdaki gibidir:

Tablo 2: Vardiyalara Göre Çalışma Saatleri

\begin{tabular}{|c|c|c|}
\hline VARDİYALAR & SAAT ARALIĞI & TOPLAM SAAT \\
\hline 1. Vardiya & $08: 30-17: 30$ & 8 \\
\hline 2. Vardiya & $18: 00-21: 00$ & 3 \\
\hline
\end{tabular}

İşletmede haftanın 6 günü çalışılmaktadır. Hafta içi günlerde ilk vardiya 8 saatlik (08:30-17:30 aras1) bir mesaiyi kapsarken, cumartesi günleri personel 5 saatlik (09:00-14:30 arası) bir çalışma yapmaktadır.

İşletmenin hafta tatili Pazar günüdür. Tüm çalışanlar hafta tatillerini Pazar günü kullanılmaktadır. Bunun yanı sıra cumartesi günleri akşam vardiyası çalışması yapılmamaktadır. Haftalık 45 saatlik normal sürelerle çalışma 6 günlük gündüz vardiyası ile doldurulduğundan akşam vardiyasında personelin maaşı 4857 sayılı İş Kanunu'na göre $\% 50$ zamlı olarak personelin saat ücreti üzerinden hesaplanarak ödenmektedir. Buna göre prototip departmanı çalışanı 11 personelin gündüz vardiyası ücretleri ve zamlı olarak ödenen akşam vardiyası ücretleri insan kaynakları departmanı ile görüşülerek alınmıştır. Vardiyaya göre ödenen ücretler aşağıdaki Tablo 3 'te gösterilmektedir:

Tablo 3: Vardiyalara Göre Personele Ödenen Ücret

\begin{tabular}{|c|c|c|}
\hline PERSONEL & 1. VARDIY ÄCRETİ (TL) & 2. VARDIYY ÜCRETI (TL) \\
\hline A & 213,30 & 120,00 \\
\hline B & 95,51 & 52,62 \\
\hline C & 182,24 & 102,50 \\
\hline D & 231,11 & 129,98 \\
\hline E & 115,60 & 65,00 \\
\hline F & 114,80 & 64,56 \\
\hline G & 138,00 & 77,60 \\
\hline H & 74,60 & 42,00 \\
\hline I & 76,80 & 43,20 \\
\hline J & 72,53 & 40,76 \\
\hline K & 200 & 112,5 \\
\hline
\end{tabular}

Tablodan da görüldüğü üzere personellerin aldıkları ücretler arasında yüksek farklılıklar bulunmaktadir. $\mathrm{Bu}$ durum da sezgisel olarak 2. vardiyaya personel ataması yapan departman üretim sorumlusunu zora sokmaktadır.

$\mathrm{Bu}$ çalışmada yukarıda bilgileri verilmiş olan departmanda enjektör üretimi için işgücü çizelgelemesi yapılacaktır. Çizelgelemesi yapılacak iş daha önce 
departmanda bir kez üretilmiş olduğu için kişilerin gündüz vardiyası üretim adetleri departman üretim sorumlusundan alınarak, kişilerin üretim adet aralıkları gri aralıksal sayı biçiminde kullanılmıştır. Departmanda sürekli değişen nitelikte işler yapılması ve üretim adetlerinin seri üretimin yanında çok daha küçük hacimlerde olması sebebiyle çizelgelemede kullanılacak olan planlama periyodu haftalık olarak belirlenmiştir. Buna göre departman üretim sorumlusundan elde edilen bilgilerle kişilere göre üretim adeti gri aralıksal sayıları Tablo 4 'te verilmektedir:

Tablo 4: Personelin Gri Aralıksal Üretim Çıktısı Adetleri

\begin{tabular}{|c|c|c|}
\hline$(\boldsymbol{i})$ & \multicolumn{2}{|c|}{$\otimes \boldsymbol{x}=[\underline{G}, \overline{\boldsymbol{G}}]$ olmak üzere } \\
\hline PERSONEL & $\underline{\boldsymbol{G}}$ & $\underline{\boldsymbol{G}}$ \\
\hline $\mathrm{A}$ & 12 & 8 \\
\hline B & 8 & 6 \\
\hline C & 11,5 & 7 \\
\hline D & 10 & 7,5 \\
\hline E & 12 & 9 \\
\hline F & 6 & 4 \\
\hline G & 6 & 3 \\
\hline H & 7,5 & 5 \\
\hline I & 5 & 3,5 \\
\hline J & 9,5 & 6 \\
\hline K & 8,5 & 6 \\
\hline
\end{tabular}

Çizelgelemesi yapılacak işin üretim adeti de gri belirsizliğin etkisi altındadır. Prototip departmanına gelen iş emirleri müşterilerin acil ihtiyaç duyduğu çıktı kalemlerinden oluşmaktadır. Müşteriler genellikle aciliyeti olan bu ürün kalemlerine olan ihtiyaç adetini üretim sürecinde yaşanan çeşitli olaylar sonucunda değişkenlik gösterebilmesi sebebiyle tam olarak saptayamamaktadır. Bu nedenle departmana gelen iş emrinin müşteri talebiyle revize edilerek üretim adetinin arttırılması sıklıkla yaşanan bir durumdur. Bu durumun bir sonucu olarak da çizelgeleme yapılırken üretim adeti müşterinin ilk siparişinin $\% 10$ fazlası üretilecek biçimde planlama yapılmalıdır. Bu uygulamada ele alınan ürünün (enjektör) üretilmek istenen gri aralıksal değeri $\otimes \mathrm{b}_{\mathrm{h}=}[580,638]$ biçiminde ifade edilmektedir. Bunun yanı sıra üretim sürecindeki adetin belirsizliği nedeniyle bütçe de gri belirsizliğin etkisi altındadır. Aylık olarak departmana tanınan akşam vardiyası bütçesinin gelecekteki projelerin durumu bilinemediğinden ne kadarının haftalık olarak harcanması gerektiği ancak gri aralıksal sayı olarak tanımlanabilmektedir. Buna göre haftalık akşam vardiyası bütçesi ele alınmakta olan enjektör ürününün üretimi için departman üretim sorumlusu tarafindan $\otimes b_{h}=[1500,1750]$ biçiminde gri aralıksal sayı olarak belirlenmiştir. 


\section{2. İşücü Çizelgelemede Kullanılan Hedef Programlama Modeli}

Departmanda yapılmakta olan çizelgelemenin iki hedefi bulunmaktadır. Bunlardan ilki haftalık üretim sipariş adetine ulaşılması diğeri ise personelin akşam vardiyasında çalıştırılması amacıyla ayrılan haftalık vardiya ücretinin aşılmamasıdır. Karar probleminin matematiksel olarak modellenmesinde kullanılacak olan indisler ve şu şekildedir:

n: Çalışan sayısı,

m: Planlama periyodundaki gün sayısı,

p: Vardiya sayıs1,

$f:$ Hedef Kısitı Sayıs1,

$h$ : Hedef indisi,

$d_{h}^{-}=h$. Hedeften yaşanan negatif sapma,

$d_{h}^{+}=h$. Hedeften yaşanan pozitif sapma,

$i$ : Çalışan indisi $(i=1,2, \ldots, n)$,

$j$ : Günler indisi $(i=1,2, \ldots, n)$,

$k$ : Vardiya indisi $(k=1,2)$,

$\bigotimes$ : Gri aralıksal sayı,

$w_{h}=h$. Hedef sapmalarının ağırlığ,

$a_{i j k}=i$. personelin $j$. günde $k$. vardiyada yaptı̆̆ üretim miktarı,

$c_{i j 2}=i$. personelin $\mathrm{j}$. günde 2 . vardiyada çalıştığ 1 için alacağ $\mathrm{ücret}$.

$x_{i j k}, i$. personelin $j$. günde $k$. vardiyada çalışması durumunda 1 , diğer durumlarda 0 değerini almaktadır.

İşletmenin hedeflerini oluşturan üretim adeti ve vardiye ücreti bütçesi hedef ksıtları aşağıdaki gibi oluşturulmaktadır.

$\circ \underline{\text { Haftalık Üretim Adetinin } \otimes b_{i}=[580,638] \text { Adetten Az Olmaması Hedef }}$ $\underline{\text { Kisıtı }}$ 


$$
\sum_{j}^{m} \otimes \mathrm{a}_{\mathrm{ijk}} \mathrm{x}_{\mathrm{ijk}}+\otimes d_{1}^{-}-\otimes d_{1}^{+} \quad \geq[580,638]
$$

$\circ \underline{\text { Haftalık Vardiva Ücreti Bütcesinin } b_{i}=[1500,1750]^{\prime} \text { den Az Olması Hedef }}$ $\underline{\text { Kisit! }}$

$$
\sum_{j}^{m} c_{\mathrm{ij} 2} \otimes \mathrm{x}_{\mathrm{ij} 2}+\otimes d_{1}^{-}-\otimes d_{1}^{+} \quad \leq[1500,1750]
$$

(12)Hedeflerden yaşanacak sapmaların ağırlıklarının belirlenmesinde gri objektif ağırlık skalasından faydalanılmıştır. Departman üretim sorumlusu ve üretim mühendisine haftalık üretim adeti ve haftalık üretim bütçesi kısıtlarının sağlanmasının önem düzeyini objektif gri ağırlık skalasına göre seçerek belirtmeleri istenmiştir. İlgili skala ve verilen yanıtlar Tablo 5'te gösterilmektedir:

\begin{tabular}{|c|c|c|c|c|c|c|c|c|}
\hline & Skala & $\begin{array}{c}\text { Çok } \\
\text { Düşük }\end{array}$ & Düşük & $\begin{array}{c}\text { Orta } \\
\text { Düşükk }\end{array}$ & Orta & $\begin{array}{c}\text { Orta } \\
\text { Yüksek }\end{array}$ & Yüksek & $\begin{array}{c}\text { Çok } \\
\text { Yükssek }\end{array}$ \\
\hline \multirow{3}{*}{$\begin{array}{l}\text { Üretim } \\
\text { Hedefi }\end{array}$} & $\otimes w_{i}$ & {$[0.0,0.1]$} & {$[0.1,0.3]$} & {$[0.3,0.4]$} & {$[0.4,0.5]$} & {$[0.5,0.6]$} & {$[0.6,0.9]$} & {$[0.9,1]$} \\
\hline & 1.kişi & & & & & & & $X$ \\
\hline & 2.kişi & & & & & & $\mathrm{X}$ & \\
\hline \multirow{2}{*}{$\begin{array}{l}\text { Vardiya } \\
\text { Bütçesi } \\
\text { Hedefi }\end{array}$} & 1.kişi & & & X & & & & \\
\hline & 2.kişi & & & $X$ & & & & \\
\hline
\end{tabular}

Tablo 5: Objektif Gri Ağırlık Skalası ve Karar Verici Yanıtları

Kaynak: (Memon, Li, Mari ve Cho, 2014, ss. 4)

Elde edilen yanıtlar gri sayıların geometrik ortalaması işlemine aşağıdaki formüle göre tabi tutularak amaç fonksiyonundaki sapma değişkenlerinin ağırlığına $\otimes w_{1}=$ $[0,73 ; 0,94]$ ve $\otimes w_{2}=[0,3 ; 0,4]$ olmak üzere ulaşılmıştır.

$$
\otimes \mathrm{w}_{\mathrm{h}}=\sqrt[k]{\otimes G_{1} \times \otimes G_{2} \mathrm{x} \otimes G_{3}}
$$

- Modelin amac fonksivonu: Modelde tanımlanmış olan haftalık üretim adeti hedefinden pozitif sapmalar kabul görürken, hedeften yaşanacak negatif sapmalar minimize edilmek istenmektedir. Haftalık vardiya ücreti bütçesi kısııında ise negatif sapmalar kabul edilirken, hedeften yaşanacak pozitif sapmaların minimize edilmesi istenmektedir. Buna göre modelin amaç fonksiyonu şu şekilde ifade edilmektedir: 


$$
\begin{gathered}
\operatorname{Min} \otimes z=\otimes w_{1} \otimes d_{1}^{-}+w_{2} \otimes d_{2}^{-} \\
x \in F \\
\otimes x_{i j}, \otimes d^{-}, \otimes d^{+} \geq 0 \\
\otimes w_{i}>0
\end{gathered}
$$

Modelde kullanılan sistem kısıtları aşağıdaki biçimde oluşturulmaktadır.

○ Hafta İci Günlerde Akșam Vardiyasında En Az İki Kișinin Calıșması Sistem Kısıtı: İş sağlığı ve güvenliği uygulamaları gereği akşam vardiyasında personelin tek başına kalması mümkün olmamaktadır. Olası bir iş kazası veya sağlık sorununda bir kişinin daha müşahitlik edebilmesi amacıyla hafta içi günlerde akşam vardiyasında minimum iki personel çalıştırılmaktadır. Bu durumu gösteren kısıt aşağıdaki şekilde modellenmektedir:

$\sum_{j}^{m} x_{i j 2} \geq 2$

○ Cumartesi Günü Akșam Vardiyasına Hiçbir Personelin Yazılmaması Sistem

Kısıtı: Personeller cumartesi günleri akşam vardiyasında çalışmak istemediklerini belirtmişlerdir. Bu durumu sağlayan kısıt aşağıdaki gibidir:

$$
\sum_{j}^{m} x_{i 62}=0
$$

- Tüm Personelin Hafta İci Gündüz Vardiyasında Calıșması Sistem Kısıtı: Departmanın çalışma prensibi gereği ve haftalık 45 saatlik çalışma süresini sağlamak adına tüm personel hafta içi günlerinde gündüz vardiyasına yazılmaktadır. Bu durum aşağıdaki kısıt ile sağlanmaktadır:

$$
\sum_{j}^{m} x_{i j 1}=11
$$

- Tüm Personelin Hafta Sonu Gündüz Vardiyasında Calıșması Sistem Kısıtı: Departmanın çalışma prensibi gereği ve haftalık 45 saatlik çalışma süresini sağlamak adına tüm personel hafta sonu gündüz vardiyasına yazılmaktadır. $\mathrm{Bu}$ durum aşağıdaki kısıt ile sağlanmaktadır:

$$
\sum_{j}^{m} x_{i 61}=11
$$

- Personelin Ardısık Günlerde Akșam Vardiyasına Yazılmaması Sistem Kısıtı: Personel ardışık günlerde akşam vardiyasında çalışmak istememektedir. Modelde personelin ardışık günlerde nöbet tutması engellenerek yorgunluk düzeyleri 
azaltılmaya çalışılmıştır. Bu durum aşağıdaki biçimde modellenmektedir:

$$
x_{i j 2}+x_{i(j+1) 2} \leq 1
$$

- Personele En Az 1 Akşam Vardiyası Yazılması Sistem Kısıtı: Akşam vardiyaları personel tarafından ek gelir olarak değerlendirilmektedir. Bu sebeple akşam vardiyasında çalışmak departman personeli tarafından arzu edilen bir durumdur. Departmandaki çalışma başarısının sürdürülebilmesi adına modelde her personele en az 1 adet akşam vardiyası yazılacak şekilde kısıtlama yapılmıştır.

$$
\sum_{j}^{m} x_{i j 2} \geq 2
$$

- $\underline{X}_{\mathrm{I}_{j k}}$ Değerlerinin 0 ya da 1 Değerini Alması Sistem Kısıtı: Vardiyalara atama gerçekleştirileceği için modeldeki $x_{i j k}$ değişkenleri 0 ya da 1 değeri alacak biçimde kisitlanmiştır.

- Haftalık Üretim Miktarı Hedefinden Yașanacak Sapmaların Tam Sayılı Olması Sistem Kısıtı: Yapılan üretim sonucunda tam sayılı çıktı değerleri elde edebilmek adına $d_{1}^{-}$değişkeni yalnızca tamsayılı değerler alabilecek biçimde kısıtlanmıştır.

\section{3. Çözüm Metodolojisi}

Literatürde Gri Hedef Programlama'nın çözümü ile ilgili açık ve ayrıntılı bir kaynak bulunmamaktadır. Yapılmış olan çalışmalarda genellikle model paylaşılmış, fakat çözüm metodolojisi aktarılmamıştır. 3.3'te belirtildiği üzere literatürdeki çalışmalarda beyazlaştırma işlemi kullanılarak çözüme gidildiği görülmektedir. Hedef Programlama'nın doğrusal programlamanın uzantısı niteliğinde olması bakımından çözüm yöntemi olarak beyazlaştırma işlemine göre çözüm sunan, Gri Sistem Teorisi'nin en çok atıf alan isimlerinden Sifeng Liu'nun 2006 yılında önerdiği, Gri Sistem Teorisi'nin en çok başvurulan kitaplarından "Grey Information: Theory and Practical Applications" adlı kitabında yer alan "Doğrusal Programlamanın Konumlandırılmış Çözümü” yaklaşımı kullanılacaktır.

- İdeal Modele Göre İsgücü Cizelgeleme Karar Probleminin Cözümü: Tanımlanmış olan Hedef Programlama modelinin amacı hedeflerden yaşanacak sapmaları minimize etmektir. Bu amaçla gri değişkenlerin beyazlaştırma faktörü kullanılarak aşağıdaki formül vasıtasıyla beyazlaştırılması gerekmektedir:

$$
\otimes=p \cdot \underline{a}+(1-\mathrm{p}) \cdot \bar{a}
$$

Model için olumlu bir durumu ifade eden kişilerin üretim miktarlarının yüksek olması durumunun ideal modele yansitılabilmesi amacıyla $p=0$ seçilmektedir. 
Haftalık vardiya bütçesi arttıkça bu durum modele olumlu olarak yansıyacağından ilgili parametrenin kullanılmasında $\beta=0$ olarak seçilmektedir.

Modelde kullanılan ağırlık değişkenlerinin alt ve üst sınırlarının modelin ideal ya da kritik olmasına bir katkısı yoktur. Bu sebeple ideal ve kritik modelin çözümünde amaç fonksiyonunda bulunan ağırlık değişkenlerinin beyazlaştırılmasında $\delta=0,5$ olarak seçilmektedir.

Sonuç olarak amacı hedeften sapmaları minimize etmek olan işgücü çizelgeleme karar problemi modeli en ideal çözüme ulaşabilmek için modelde $\rho=\beta=0, \delta=$ 0,5 beyazlaştırma faktörlerleri kullanılmıştır; yani $L P(0 ; 0 ; 0,5)$ modeli kurulmuştur. Böylece min $\underline{S}$ 'ye, yani minimizasyon amacı taşıyan doğrusal programlama modeli çözümünün en ideal durumuna ulaşılacaktır.

Model Excel Solver üzerinde 27 iterasyonda çözdürülmüştür. Çözümün sonucunda haftalık vardiya bütçesinden 1727,44 TL kullanılmış, hedeften istenmeyen pozitif sapma yaşanmamıştır. Çözüm sonucuna göre yapılan işgücü çizelgeleme ile 622 adet enjektör ürünü üretilecektir. Kurulmuş olan $L P(0 ; 0 ; 0,5)$ Gri Doğrusal Programlama modelinin çözümünden elde edilen çözüm değeri $\min S(0 ; 0 ; 0.5)=$ 16'dır. $\mathrm{Bu}$ durumda haftalık üretim miktarı hedefinden 16 adetlik sapma görülmektedir.

Kritik Modele Göre İsgücü Cizelgeleme Karar Probleminin Cözümü: Model için olumsuz bir durumu ifade eden kişilerin üretim miktarlarının düşük olması durumunun kritik modele yansıtılabilmesi amacıyla beyazlaştırma faktörü $p=1$ olarak seçilmektedir.

Haftalık vardiya bütçesi azaldıkça bu durum modele olumsuz olarak yansıyacağından ilgili parametrenin beyazlaştırılmasında beyazlaştırma faktörü $\beta=1$ olarak biçimde tercih edilmektedir.

Modelde kullanılan ağırlık değişkenlerinin alt ve üst sınırlarının modelin ideal ya da kritik olmasına bir katkısı yoktur. Bu sebeple ideal ve kritik modelin çözümünde amaç fonksiyonunda bulunan ağırlık değişkenlerinin beyazlaştırılmasında $\delta=$ 0,5 olarak seçilmiştir.

Sonuç olarak amacı hedeften sapmaları minimize etmek olan işgücü çizelgeleme karar problemi modeli kritik çözüme ulaşabilmek amacıyla modelde $\rho=\beta=$ $1, \delta=0,5$ beyazlaştırma faktörlerleri kullanılmıştır ve $L P(1 ; 1 ; 0,5)$ modeli kurulmuştur. Böylece min $\bar{S}$ 'ye, yani minimizasyon amacı taşıyan doğrusal programlama modeli çözümünün kritik durumuna ulaşılacaktır.

Model Excel Solver üzerinde 41 iterasyonda çözdürülmüştür. Çözümün sonucunda haftalık vardiya bütçesinden 1457,88 TL kullanılmış, hedeften istenmeyen pozitif sapma yaşanmamıştır. Çözüm sonucuna göre yapılan işgücü çizelgeleme ile 4156 
adet enjektör ürünü üretilecektir. Kurulmuş olan $L P(1 ; 1 ; 0,5)$ Gri Doğrusal Programlama modelinin çözümünden elde edilen çözüm değeri $\min S(1 ; 1 ; 0,5)=$ 165'tir. $\mathrm{Bu}$ durumda haftalık üretim miktarı hedefinden 165 adetlik sapma görülmektedir.

\section{$\underline{\theta}$ Konumlandırılmıs Modele Göre İsgücü Cizelgeleme Karar Probleminin}

C̈özümü: Konumlandırılmış modelde beyazlaştırma faktörleri $\rho=\beta=\delta=\theta$ biçiminde kullanılır. yani $L P(\theta)$ modeli kurulmaktadır. Buna göre sırasıyla 0,5; 0,75 ve 0,25 için konumlandırılmış Gri Doğrusal Programlama modeli çözülüp tatmin dereceleri hesaplanacaktır.

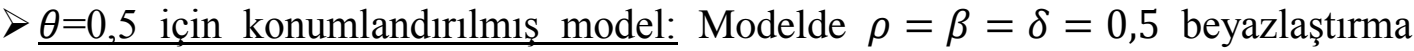
faktörlerleri kullanılmıştır, yani $L P(0,5)$ konumlandırılmış modeli kurulmuştur.

Model Excel Solver üzerinde 20 iterasyonda çözdürülmüştür. Çözümün sonucunda haftalık vardiya bütçesinden 1619,68 TL kullanılmış, haftalık vardiya bütçesi hedefinden istenmeyen pozitif sapma yaşanmamıştır. Çözüm sonucuna göre yapılan işgücü çizelgeleme ile 518 adet enjektör ürünü üretilecektir. Bu durumda haftalık üretim miktarı hedefinden 91 adetlik sapma görülmektedir. Kurulmuş olan $\operatorname{LP}(0,5)$ Gri Doğrusal Programlama modelinin çözümünden elde edilen çözüm değeri $\min S(0,5)=91^{\prime}$ dir $\rho, \beta, \delta \in[0,1]$ olmak üzere $L P(0,5)$ modeli için konumlandırılmış Gri Doğrusal Programlama'nın tatmin derecesi aşağıdaki biçimde hesaplanmaktadir.

$$
\mu(\rho, \beta, \delta)=\frac{1}{2}\left(1-\frac{16}{91}\right)+\frac{1}{2}\left(1-\frac{91}{165}\right)=0,6363
$$

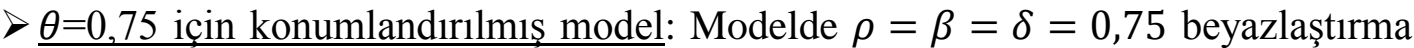
faktörlerleri kullanılmıştır, yani $L P(0,75)$ konumlandırılmış modeli oluşturulmuştur.

Model Excel Solver üzerinde 14 iterasyonda çözdürülmüştür. Çözümün sonucunda haftalık vardiya bütçesinden 1560 TL kullanılmış, haftalık vardiya bütçesi hedefinden istenmeyen pozitif sapma olmamıştır. Çözüm sonucuna göre yapılan işgücü çizelgeleme ile 467 adet enjektör ürünü üretilecektir. Bu durumda haftalık üretim miktarı hedefinden 127 adetlik sapma görülmektedir. Kurulmuş olan $L P(0,75)$ Gri Doğrusal Programlama modelinin çözümünden elde edilen çözüm değeri $\min S(0,75)=127^{\prime}$ dir.

$\rho, \beta, \delta \in[0,1]$ olmak üzere $L P(0,5)$ modeli için konumlandırılmış Gri Doğrusal Programlama'nın tatmin derecesi aşağıdaki biçimde hesaplanmıştır.

$$
\mu(\rho, \beta, \delta)=\frac{1}{2}\left(1-\frac{16}{127}\right)+\frac{1}{2}\left(1-\frac{127}{165}\right)=0,7375
$$




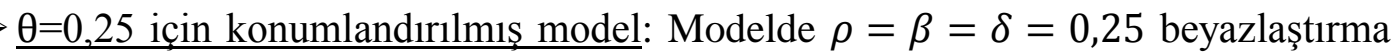
faktörlerleri kullanılmıştır, yani $L P(0,25)$ konumlandırılmış modeli kurulmuştur.

Model Excel Solver üzerinde 14 iterasyonda çözdürülmüştür. Çözümün sonucunda haftalık vardiya bütçesinden 1684,24 TL kullanılmış, haftalık vardiya bütçesi hedefinden istenmeyen pozitif sapma yaşanmamıştır. Çözüm sonucuna göre yapılan işgücü çizelgeleme ile 570 adet enjektör ürünü üretilecektir. Bu durumda haftalık üretim miktarı hedefinden 53 adetlik sapma görülmektedir. Kurulmuş olan $L P(0,25)$ Gri Doğrusal Programlama modelinin çözümünden elde edilen çözüm değeri $\min S(0,25)=53^{\prime}$ tür.

$\rho, \beta, \delta \in[0,1]$ olmak üzere $L P(0,25)$ modeli için konumlandırılmış Gri Doğrusal Programlama'nın tatmin derecesi aşağıdaki biçimde hesaplanmaktadır.

$$
\mu(\rho, \beta, \delta)=\frac{1}{2}\left(1-\frac{16}{53}\right)+\frac{1}{2}\left(1-\frac{53}{164}\right)=0,687
$$

Literatürde konumlandırılmış modelin iyileştirilmesi amacıyla beyazlaştırma faktörünün seçimine ilişkin tanımlanmış bir sistematik bulunmamaktadır. $\mathrm{Bu}$ sebeple yöntemde seçilen beyazlaştırma faktörleri sezgiseldir. Nihayetinde ele alınan karar problemi için 5 farklı konumlandırılmış model oluşturularak çözümleri gerçekleştirilmiştir. Bu modellerin çözümünden elde edilen sonuçlar Tablo 6'da özetlenmektedir.

Tablo 6: Uygulama Modelleri Karşılaştırmalı Sonuç Tablosu

\begin{tabular}{|c|c|c|c|c|c|c|c|}
\hline Model & $\begin{array}{c}\mathrm{d}_{1}^{-} \\
\text {Üretim } \\
\text { Kisıtından } \\
\text { Negatif } \\
\text { Sapma }\end{array}$ & $\begin{array}{c}\mathbf{d}_{2}^{+} \\
\text {Bütçe } \\
\text { Kısitından } \\
\text { Pozitif } \\
\text { sapma }\end{array}$ & $\begin{array}{c}\mathbf{b}_{1} \\
\text { Üretim } \\
\text { Kısıtının } \\
\text { Sağ } \\
\text { Tarafı }\end{array}$ & $\begin{array}{c}\mathbf{b}_{\mathbf{2}} \\
\text { Bütçe } \\
\text { Kısıtının } \\
\text { Sağ } \\
\text { Tarafı }\end{array}$ & $\begin{array}{l}\text { Üretim } \\
\text { Adeti }\end{array}$ & $\begin{array}{c}\text { Kullanılan } \\
\text { Bütçe }\end{array}$ & $\begin{array}{l}\text { Tatmin } \\
\text { Düzeyi }\end{array}$ \\
\hline İdeal & 16 & 0 & 638 & 1750 & 622 & 1727,44 & - \\
\hline Kritik & 165 & 0 & 580 & 1500 & 415 & 1457,88 & - \\
\hline$L P(0,50)$ & 91 & 0 & 609 & 1625 & 518 & 1619,68 & 0,6363 \\
\hline$L P(0,75)$ & 127 & 0 & 594 & 1562,5 & 467 & 1560 & 0,7375 \\
\hline$L P(0,25)$ & 53 & 0 & 623 & 1687,5 & 570 & 1684,24 & 0,687 \\
\hline
\end{tabular}

Literatürde minimizasyon amacı taşıyan konumlandırılmış Gri Doğrusal Programlama çalışması bulunmamaktadır. Liu ve Dang 2009 yılındaki çalışmalarında maksimizasyon amacı taşıyan karar modelleri için $\mu(\theta)$ değeri yükseldikçe ideal değere yaklaştı̆̆ 1 ve tatmin ediciliğinin arttığını açıklamaktadır (Liu ve Dang, 2009, s. 755). Bu durumun minimizasyon amaçlı fonksiyonlarda tersi olması beklenmektedir. Minimizasyon amaçlı fonksiyonlarda en ideal çözüm en düşük sonucu veren çözümdür. Buna göre Liu ve Dang'in yapmış oldukları açıklamaya göre ele alınmış karar problemi için Tablo 6'da görüldüğü üzere en 
düşük $\mu(\theta)$ değerine sahip $L P(0,5)$ 'in en tatmin edici konumlandırılmış model olduğu sonucuna varılmaktadır. Zaten Liu ve Lin çalışmalarında dağılım fonksiyonu bilinmeyen durumlarda kullanılması en uygun beyazlaştırmanın eşit ağırlıklı beyazlaştırma olduğundan bahsetmektedir. Yine aynı çalışmada Gri Sistem Teorisi'nde beyazlaştırma amacıyla en sık kullanılan beyazlaştırma faktörünün 0,5 ; yani eşit ağırlıklı beyazlaştırma olduğu bilgisi bulunmaktadır. (Liu ve Lin, 2006, s. 25) Bu yönüyle uygulamadan elde edilen sonuçlar literatürdeki sonuçlarla tutarlılık taşımaktadır.

Yapılan analizler sonucunda farklı konumlandırılmış modellere göre personele yazılacak akşam vardiyası sayılarında da farklılık olduğu görülmüştür. Bu durum Tablo 7'de özetlenmektedir.

Aynı şekilde farklı konumlandırılmış modellere göre her gün akşam vardiyasında çalışacak personel sayısında da farklılık olduğu görülmektedir. Bu durum Tablo 8 'de gösterilmektedir:

Tablo 7: Modellere Göre Personele Yazılan Akşam Vardiyası Sayıları

\begin{tabular}{|c|c|c|c|c|c|c|c|c|c|c|c|}
\hline \multicolumn{10}{|c|}{ i. } \\
\hline MERSONEL \\
\hline Model & $\mathbf{1}$ & $\mathbf{2}$ & $\mathbf{3}$ & $\mathbf{4}$ & $\mathbf{5}$ & $\mathbf{6}$ & $\mathbf{7}$ & $\mathbf{8}$ & $\mathbf{9}$ & $\mathbf{1 0}$ & $\mathbf{1 1}$ \\
\hline İdeal & 2 & 3 & 3 & 1 & 3 & 2 & 1 & 3 & 3 & 3 & 1 \\
\hline Kritik & 2 & 3 & 1 & 1 & 3 & 1 & 1 & 3 & 3 & 3 & 1 \\
\hline $\boldsymbol{L P}(\boldsymbol{0 , 5 0})$ & 2 & 3 & 3 & 1 & 3 & 1 & 1 & 3 & 2 & 3 & 1 \\
\hline $\boldsymbol{L P}(\mathbf{0}, 75)$ & 2 & 3 & 2 & 1 & 3 & 1 & 1 & 3 & 3 & 3 & 1 \\
\hline $\boldsymbol{L P}(\boldsymbol{0}, 25)$ & 2 & 3 & 3 & 1 & 3 & 2 & 1 & 3 & 2 & 3 & 1 \\
\hline
\end{tabular}

Tablo 8: Günlere Göre Akşam Vardiyasında Görevli Personel Sayıları

\begin{tabular}{|c|c|c|c|c|c|}
\hline \multicolumn{7}{|c|}{ J. Gün } \\
\hline Model & Pazartesi & Salı & Çarşamba & Perşembe & Cuma \\
\hline İdeal & 7 & 3 & 6 & 2 & 7 \\
\hline Kritik & 6 & 2 & 5 & 2 & 7 \\
\hline $\boldsymbol{L P}(\boldsymbol{0 , 5 0 )}$ & 7 & 2 & 6 & 2 & 6 \\
\hline $\boldsymbol{L P}(\boldsymbol{0 , 7 5 )}$ & 6 & 2 & 6 & 2 & 7 \\
\hline $\boldsymbol{L P}(\boldsymbol{0 , 2 5 )}$ & 6 & 2 & 8 & 2 & 6 \\
\hline
\end{tabular}

\section{Sonuç}


İşletmelerin çözmesi gereken karar problemlerinden biri de işgücü çizelgeleme karar problemleridir. İşletmeler belirli bir işi minimum işgücü kullanarak gerçekleştirmek istemektedirler. Bunu yaparken işletmeler aynı zamanda sınırlı maliyetle, belirli bir sürede, belirli sayıda üretim yapmak gibi çeşitli amaçlar taşımaktadırlar. Bu sebeple işgücü çizelgeleme karar problemleri çok amaçlı karar verme yöntemleri ile ele alınması gereken karar problemleridir.

İşü̈ü çizelgeleme karar problemlerinin modellenmesi ve çözümünde pek çok farklı yöntem kullanılmaktadır. Fakat işgücü karar problemlerinin çok amaçlı yapısı gereği Hedef Programlama yöntemi literatürde işgücü çizelgeleme karar problemlerinin çözümünde sıklıkla başvurulan bir yöntemdir.

$\mathrm{Bu}$ çalışmanın uygulamasının yapıldığı işletmede prototip departmanında işgücü çizelgelemesi ele alınmıştır. Prototip departmanı seri üretim sürecine sokulması maliyetli olan ürünlerin tek seri olarak üretildiği, aynı işin yılda maksimum üç kez yapıldığı, çoğunlukla haftalık iş emirleri ile çalışan bir departmandır. Departmanın çalışma prensipleri gereği işgücü çizelgelemesi yapılırken sipariş adeti, akşam vardiyasına ayrılan bütçe ve çalışanların üretim performansları gri belirsizliğin etkisi altındadır. Bu değişkenlere ilişkin parametreler ancak gri aralıksal sayı olarak tanımlanabilmektedir.

Bu çalışmada gri belirsizliğin etkisi altındaki karar probleminin belirlenmesinde Gri Hedef Programlama yöntemi kullanılmıştır. Literatürde özel olarak tanımlanmış bir Gri Hedef Programlama yöntemi bulunmamaktadır. Bu sebeple Hedef Programlama yöntemi doğrusal programlamanın özel bir versiyonu olduğundan literatürde tanımlanmış olan Sifeng Liu'nun önerdiği “Gri Doğrusal Programlama'nın Konumlandırılmış Çözümü” kullanılmıştır. Yönteme uygun olarak ikisi "ideal model" ve "kritik model" olarak adlandırılmak üzere toplam 5 adet model kurulmuş ve oluşturulan modeller Excel Solver yardımıyla çözülmüştür. Liu ve Dang'in 2009 yılındaki çalışmalarındaki açıklamalarına göre minimizasyon amacı taşıyan fonksiyonlar $\mu(\theta)$ değeri düşük olan konumlandırılmış modelin tatmin ediciliğinin daha yüksek olacağı görülmektedir. Buna göre $\mu(\theta)$ değerine göre tatmin ediciliği en düşük model $L P(0,75)$ iken, tatmin ediciliği en yüksek konumlandırılmış modelin $L P(0,50)$ olduğu sonucuna ulaşılmıştır. Çözüm sonucunda işletmenin $L P(0,50)$ konumlandırılmış modeli kullanması gerektiği görülmüştür.

Yapılan analizler incelendiğinde kurulmuş modellere göre personel başına yazılan akşam vardiyası sayısının ve günlere göre akşam vardiyasında çalışan personel sayısının farklılık gösterdiği anlaşılmaktadır. Uygulamada çözülmüş olan karar problemi karar vericinin sezgisel olarak çözemeyeceği karmaşıklıktadır. Uygulama öncesinde yaşanan planlama sorunları önerilmiş olan yöntemle ortadan kaldırılmıştır. Yapılmış olan uygulama sektörde her hafta uygulanabilecek pratikliktedir. 
Bundan sonraki çalışmalarda gri hedef programlanın diğer Gri Doğrusal Programlama yöntemleri ile modellenmesi incelenebilir. Aynı zamanda Gri Doğrusal Programlama'nın konumlandırılmış çözümünde genetik algoritma gibi yöntemler kullanılarak hangi konumlandırılmış modelin seçilmesi gerektiği konusuna katkı sağlanabilir. Yöntemde hesaplaması yapılan tatmin derecesi için alternatif fonksiyonlar çalışılabilir. İşgücü çizelgeleme karar problemlerinin eksik/yetersiz bilginin etkisi altında olması halinde farklı sektörlerde de Gri Hedef Programlama kullanılabilir. Uygulamanın temelini oluşturan Gri Doğrusal Programlama'nın farklı doğrusal programlama tabanlı yöntemlerle birleştirilmesi sonucunda hibrit çalışmalar yapılabilir. Ayrıca yöntemin bulanık ve stokastik belirsizlik modellerinin sonuçları ile karşılaştırmalı olarak ele alınabileceği de düşünülmektedir. 


\section{Kaynakça}

Akdeniz, A. ve Aras, A. (2010). İzmir'de kurulu bir plastik işletmesinde karar vericinin optimal hedeflere odaklanmasinda toplamsal model tabanlı bulanık hedef programlama, Dokuz Eylül Üniversitesi Sosyal Bilimler Enstitüsü Dergisi, 12(3). 719.

Askari, M. ve Askari, H. (2011). Time series grey system prediction-based models, gold price forecasting, Trends in Applied Sciences Research, 6(11). 1287-1292.

Atmaca, Ü. (2002). Bankacılık sisteminde organizasyon yapısındaki değişim ve doğru ölçeği bulma, Gazi Üniversitesi Sosyal Bilimler Enstitüsü Dergisi, 14, 91103.

Aykin, T. (2000). A comparative evaluation of modelling approaches to the labor shift scheduling problem, European Journal of Operational Research. 125, 381397.

Azaiez, M. N. ve Al Sharif, S. S. (2005). A 0-1 goal programming model for nurse scheduling, Computers \& Operations Research, 32(3), 491-507.

Balderas, F., Fernandez, E., Gomez-Santillan, C., Cruz-Reyes, L., Rangel-Valdez, N. ve Morales-Rodríguez, M. L. (2018). A grey mathematics approach for evolutionary multi objective metaheuristic of project portfolio selection, Fuzzy Logic Augmentation of Neural and Optimization Algorithms, Theoretical Aspects and Real Applications, 749, 379-388.

Bechtold, S. E. ve Jacobs, L. W. (1990). Implicit modeling of flexible break assignments in optimal shift scheduling, Management Science, 4(42), 589-602.

Buffa, F. P. ve Jackson, W. M. (1983). A goal programming model for purchase planning, Journal of Purchasing and Materials Management, 12, 27-34.

Çelikbilek, Y. (2018). A grey analytic hierarchy process approach to project manager selection, Journal of Organizational Change Management, 31(3), 749-765.

Charnes, A. ve Cooper, W. W. (1961). Management Models and Industrial Applications of Linear Programming, New York, John Wiley and Sons.

Charnes, A., Cooper, W. W. ve Ferguson, R. O. (1955). Optimal estimation of executive compensation by linear programming, Management Science, 1(2), 138151.

Charnes, A., Cooper, W. W. (1977). Goal programming and multiple objective optimizations: Part 1. European journal of operational research, 1(1), 39-54. 
Chu, S. C. (2007). Generating, scheduling and rostering of shift crew-duties, applications at the Hong Kong International Airport, European Journal of Operational Research, 177(3), 1764-1778.

Deng, J. (1982). Control problems of grey systems, Systems and Control Letters, 5, 288-294.

Deng, J. (1982). Grey control system, Journal of Huazhong University of Science and Technology, 3, 9-18.

Deng, J. (1988). Grey System, Beijing, China Ocean Press.

Girginer, N. ve Uçkun, N. (2015). Efficiency analysis of surgical services by combined use of data envelopment analysis and gray relational analysis, Journal of Medical Systems, 56, 1-9.

Hajiagha, S. H., Akrami, H. ve Hashemi, S. S. (2012). A multi-objective programming approach to solve grey linear programming, Grey Systems, Theory and Application, 2(2), 259-271.

Hamzaçebi, C. ve Pekkaya, M. (2011). Determining of stock investments with grey relational analysis, Expert Systems with Applications, 8(38), 9186-9195 .

Hemaida, R. ve Hupfer, M. (1995). A multiobjective model for managing faculty resources, Journal of Applied Business Research, 11(1), 20-37.

Hsiao, S. W., Lin, H. H. ve Ko, Y. C. (2017). Application of grey relational analysis to decision-making during product development, Eurasia Journal of Mathematics, Science and Technology Education, 13, 2581-2600.

Hu, Y. C., Jiang, P. ve Lee, P. C. (2018). Forecasting tourism demand by incorporating neural networks into grey-markov models, Journal of The Operational Research Society, 1, 1-9.

Huarng, F. (1999). A primary shift rotation nurse scheduling using zero-one linear goal programming, Computers in nursing, 17(3), 135-144.

Ignizio, J. (1976). Goal Programming and Extensions, Washington, Lexington Books.

Ijiri, Y. (1965). Management Goals and Accounting for Control, Amsterdam, North-Holland Publishing Company.

Ishibuchi, H. ve Tanaka, H. (1990). Multiobjective programming in optimization of the interval objective function, European Journal of Operational Research, 2(48), 219-225. 
Jones, D. ve Tamiz, M. (2010). Practical Goal Programming, London, Springer Science+Business Media, LLC.

Karaman, B. ve Çerçioğlu, H. (2015). 0-1 hedef programlama destekli bütünleşik ahp-vikor yöntemi, hastane yatırımı projeleri seçimi, Gazi Üniversitesi Mühendislik Mimarlık Fakültesi Dergisi, 3(4), 567-576.

Kayacan, E. ve Okyay, K. (2010). Grey system theory-based models in time series prediction, Expert Systems with Applications, 37, 1784-1789.

Köse, E. Temiz, İ. ve Erol, S. (2011). Grey system approach for economic order quantity models under uncertainty, The Journal of Grey System, 1, 71-82.

Kwak, N. K. ve Schniederjans, M. J. (1982). An alternative method for solving goal programming problems, a reply, The Journal of The Operational Research Society, $33,859-860$.

Lee, J. W. ve Kim, S. H. (2000). Using analytic network process and goal programming for interdependent information system project selection, Computers and Operations Research, 4(27), 367-382.

Leung, L. C., Cao, D. ve Lin, T. W. (2000). On consistency and ranking of alternatives in fuzzy AHP, European Journal of Operational Research, 23, 102-124.

Li, Q. X. (2007). The cover solution of grey linear programming, The Journal of Grey System, 4, 309-320.

Liu, H. C., Liu, L., Bian, Q. H., Lin, Q. L., Dong, N. ve Xu, P. C. (2011). Failure mode and effect analysis using fuzzy evidential reasoning approach and grey theory, Expert Systems with Applications, 38, 4403-4415.

Liu, S. ve Dang, Y. (2009). On positioned solution of linear programming with grey parameters, Proceedings of The 2009 IEEE International Conference on Systems, Man, and Cybernetics, 751-756.

Liu, S. ve Lin, Y. (2006). Grey Information Theory and Practical Applications, New York, Springer.

Liu, S., Fang, Z., Yang, Y. ve Forrest, J. (2012). General grey numbers and its operations, General Grey Numbers and Their Operations, 2(3), 341-349.

Mahdiraji, H. A., Hajiagha, S. H., Hashemi, S. S. ve Zavadskas, E. K. (2016). A grey multi-objective linear model to find critical path of a project by using time, cost, quality and risk parameters, Business Administration and Management, 14, 4960 . 
Mathirajan, M. ve Ramanathan, R. (2007). A (0-1) goal programming model for scheduling the tour of a marketing executive. European Journal of Operational Research, 179(2), 554-566.

Medoza, A., Santioga, E. ve Ravindran, A. R. (2008). Three-phase multicriteria method to the supplier selection problem, International Journal of Industrial Engineering, 2(15), 195-210.

Memon, M. S., Lee, Y. H., Mari, S. I. ve Cho, S. Y. (2014). A grey-goal programming based approach for managing product safety risk in supplier selection decision, Taipei, International Symposium on Semiconductor Manufacturing Intelligence.

Moore, R. E. (1979). Methods and Applications of Interval Analysis, New York, SIAM.

Orumie, U. C. ve Ebong, D. (2014). A glorious literature on linear goal programming algorithms, American Journal of Operations Research, March, 4(1), $59-71$.

Özdemir, A. İ. ve Deste, M. (2009). Gri ilişkisel analiz ile çok kriterli tedarikçi seçimi, otomotiv sektöründe bir uygulama, Ístanbul Üniversitesi İşletme Fakültesi Dergisi, 38(2), 147-156.

Özdemir, A. ve Özdağoğlu, G. (2017). Predicting product demand from small-sized data, Grey Models, Grey Systems, Theory and Application, 7(1), 80-96.

Paksoy, T. ve Chang, C. (2010). Revised multi-choice goal programming for multiperiod, multi-stage inventory controlled supply chain model with popup stores in guerrilla marketing, Applied Mathematical Modelling, 11(34), 3586-3598.

Papageorgiou, E. I. ve Salmeron, J. L. (2012). Learning fuzzy grey cognitive maps using nonlinear hebbian-based approach, International Journal of Approximate Reasoning, 53, 54-65.

Rahimnia, F. ve Mashreghi, E. (2011). Application of grey theory approach to evaluation of organizational vision, Grey Systems, Theory and Application, 1(1), 3346.

Rajesh, R. ve Ravi, V. (2015). Supplier selection in resilient supply Chains, A grey relational analysis approach, Journal of Cleaner Production, 86, 343-359.

Roijers, D. M. ve Whiteson, S. (2017). Multi-Objective Decision Making, Texas, Morgan and Claypool Publishers. 
Romero, C. (1991). Handbook of Critical Issues in Goal Programming, New York, Pergamon Press.

Sadeghi, M., Hajiagha, S. H. ve Hashemi, S. S. (2013). A fuzzy grey goal programming approach for aggregate production planning mohammadreza, Int $J$ Adv Manuf Technol, 64, 1715-1727.

Sadeghieh, A., Dehghanbaghi, M., Dabbaghi A. ve Barak , S. (2012). A genetic algorithm based grey goal programming (g3) approach for parts supplier evaluation and selection, International Journal of Production Research, 50, 4612-4630.

Schniederjans, M. J. (1995). Goal Programming, Methodology and Applications, New York, Springer Science+Business Media, LLC.

Sinha, B. ve Sen, N. (2011). Goal programming approach to tea industry of barak valley of assam, Applied Mathematical Sciences, 5(29), 1409-1419.

Topaloğlu, S. (2006). A multi-objective programming model for scheduling emergency medicine residents, Computers \& Industrial Engineering, 51(3), 375388 .

Tseng, M. L. (2009). A causal and effect decision making model of service quality expectation using grey-fuzzy DEMATEL approach, Expert Systems With Applications, 36, 7738-7748.

Wang, Y., Tang, J. ve Cao, W. (2012). Grey prediction model-based food security early warning prediction, Grey Systems, Theory and Application, 1(2), 13-23.

Wenping, W. (1997). Study on grey linear programming, Journal of Grey Systems, 1(9), 41-46.

Xia, M. ve Wong, W. K. (2014). A seasonal discrete grey forecasting model for fashion retailing, Knowledge-Based Systems, 57, 119-126.

Xinping, X. (1998). New study on the solution of grey linear programming, Journal of Grey System, 2(10), 133-139.

Yao, A. W., Chi, S. C. ve Chen, J. H. (2003). An improved grey-based approach for electricity demand forecasting, Electric Power Systems Research, 67, 217-224.

Young, R. C. (1931). The algebra of many-valued quantities, Mathematische Annalen, 260-290. 


\section{Solution of Labor Scheduling Decision Problems with Grey Goal Programming}

\section{Extended Abstract}

\section{Introduction}

In real-world decision problems; businesses rarely have sufficient data about the decisions they will make. This leads to uncertainty. There are three most common types of uncertainty in the literature. These are; stochastic, fuzzy and grey uncertainty. The type of uncertainty encountered when there is a limited number of data so that it cannot be modeled by stochastic or fuzzy uncertainty is grey uncertainty. The main source of grey uncertainty is insufficient data. (Papageorgiou and Salmeron, 2012, p. 55).

Goal programming, which is one of the most used multi-objective decision-making methods. While linear programming models, without the goal constraints, focus only on a single objective such as profit maximization or cost minimization, goal programming aims at optimization of various conflicting goals by the objective of minimizing the undesired deviations from these goals. For this reason, the ultimate solution called optimal solution in linear programming models is also called as satisficing solution in goal programming models (Hemaida and Hupfer, 1995, p. 25).

Labor scheduling decision problem is a decision problem that decision-maker has more than one goal. In this respect, it is appropriate to use Grey Goal Programming approach in the production of prototypes where uncertainty caused by incomplete information is dominant. The aim of this study is to examine the labor scheduling decision problems with prototype production in a business that operates in the automotive sector with Grey Goal Programming approach.

\section{Method}

In this study, the labor scheduling decision problem experienced during prototype production in the prototype department of a multinational company operating in automotive sector is considered. The business has multiple goals it desires to achieve while scheduling. At the same time, the labor scheduling decision problem is under the influence of the uncertainty arising from the missing information, due to the working principles of the prototype department where the application is made. Therefore, Grey Goal Programming Method has been chosen as the solution method.

The purpose of the prototype department where the application is carried out is to make the production of the customer orders that are rarely received from these customers. The labor scheduling in the department has two goals: The first one is to reach the weekly production order quantity and the other is not to exceed the weekly shift wage allocated for the personnel to work in the night shift. While positive deviations from the weekly production quantity goal defined in the model are accepted, negative deviations from the goal are desired to be minimized. Negative deviations are accepted in the weekly shift wage budget constraint, while positive deviations from the goal are required to be minimized. The system constraints in the model are those: i. Minimum two personnel will be in the night shift every weekday, ii. No personnel will be assigned to night shift on Saturdays, iii. All personnel will be in the day shift on weekdays, iv. All personnel will be on day shift on weekends, v. The personnel shouldn't be assigned to night shift on consecutive days, vi. Minimum 1 night shift will be assigned to each personnel. The decision variables $\left(x_{i j k}\right)$ related to the assignment of $i^{\text {th }}$ personnel on day $j$ to the $k^{\text {th }}$ shift are binary variables and also the deviations from the weekly production goal should be integer.

The Grey Goal Programming method uses the same formulation as Goal Programming. The difference of the method from Goal Programming is that the parameters and solution values are displayed in grey form (Memon, Li, Mari and Cho, 2014, p. 4). When the literature on Grey Goal Programming are examined, it was seen that either little information is shared about the methodology 
used in the solution of the model or the model is evaluated as an extension of the linear programming approach and solved by using the Grey Linear Programming method.

Since goal programming is an extension of linear programming, as the solution method, The Positioned Solution of Grey Linear Programming, providing a solution according to a whitening process, proposed by Sifeng Liu (2006) will be used.

Positioned solution of grey linear programing is a type of linear programming model in which the grey parameters are used. The fundamentals of the method are based on the association of the linear programming method with grey parameters to the traditional linear programming method by whitening grey model. The most important advantage of the method is that its application is fast and easy (Liu and Lin, 2006, pp. 367-377; Liu and Dang, 2009, pp. 751-756).

\section{Results and Discussion}

There is no defined systematic selection of whitening factor in the literature in order to improve the positioned model. Therefore, the whitening factors selected in the method are intuitive. In the study, 5 different positioned models are formed for the decision problem discussed. These are; ideal, critical, LP (0.5), LP (0.75) and LP (0.25) positions. As a result of the analyzes, it was observed that there were differences in the number of evening shifts to be written to the personnel according to different positioned models and the number of personnel to work in the evening shifts each day.

\section{Conclusion}

These Positioned Grey Goal Programming Models have been solved by help of Microsoft Excel Solver using real data derived from business. As the result of the analyzes, it was concluded that the most satisfactory model was found to be according to its $\mu(\theta)$ value. Consequently; the model with the lowest satisfaction is LP (0.75) and the most satisfactory model is LP (0.5).

When the analyzes are examined, it is understood that the number of evening shifts per personnel and the number of personnel working in the evening shifts differ according to the established models. The decision problem solved in practice is so complex that the decision maker cannot intuitively solve it. Planning problems that the business is experiencing have been eliminated by the proposed method and labor scheduling decision problems are simplified with this sustainable method proposal. 